HISPANIA. Revista Española de Historia, 2009, vol. LXIX, núm. 233, septiembre-diciembre, págs. 739-768, ISSN: 0018-2141

\title{
LA ORGANIZACIÓN DE LA CAMPAÑA NAVAL DE LAS AZORES DE 1582: CORTE Y TERRITORIO EN LA MONARQUÍA DE FELIPE II *
}

\author{
SANTIAGO FERNÁNDEZ CONTI \\ Instituto Universitario «La Corte en Europa» de la UAM \\ FÉLIX LABRADOR ARROYO \\ Univ. Rey Juan Carlos / Instituto Universitario «La Corte en Europa» de la UAM
}

RESUMEN: En el presente trabajo pretendemos profundizar en el ejercicio del poder real, su mediatización cortesana y su proyección sobre el territorio a través del análisis de la organización de una campaña militar concreta: la empresa de las Azores de 1582. El bilo conductor que nos sirve para adentrarnos en este episodio es la figura de uno de los principales oficiales que tomaron parte en el mismo: el maestre de campo don Francisco de Bobadilla, futuro conde de Puñonrostro. Este análisis nos permitivá establecer las características de dos formas diferentes de relación entre los instrumentos de poder del soberano tomados éstos bien como receptores y difusores de su gracia, bien como gestores de su jurisdicción delegada; por un lado, se trata de realizar un análisis vertical, en una linea que tiene su punto superior en el monarca y concluye en los destinatarios últimos de sus órdenes y pasa por la posición intermedia de ministros y secretarios; por

Santiago Fernández Conti es investigador en el Instituto Universitario «La Corte en Europa» de la UAM. Dirección para correspondencia: Servicio de Biblioteca, Edificio Rectorado, Universidad Autónoma de Madrid, C/ Einstein, 3, 28049, Madrid.E-mail: santiago.conti@uam.es

Félix Labrador Arroyo es profesor en la Universidad Rey Juan Carlos e investigador en el Instituto Universitario "La Corte en Europa» de la UAM. Dirección para correspondencia: Departamento de Ciencias de la Educación, el Lenguaje, y la Cultura y las Artes, Campus de Fuenlabrada, Universidad Rey Juan Carlos, Camino del Molino s/n, 28943,Fuenlabrada (Madrid).E-mail: felix.labrador@urjc.es

* Este trabajo forma parte del proyecto de investigación: «Sólo Madrid es Corte. La construcción de la corte de la Monarquía Católica (siglos XVII-XVIII)» financiado por la Comunidad Autónoma de Madrid-Universidad Autónoma de Madrid número de referencia (S2007/HUM-0425). Abreviaturas utilizadas: AA: Archivo de los duques de Alba (Madrid); ACP: Archivo de los condes de Puñonrostro (Madrid); AGS: Archivo General de Simancas; CMC: Contaduría Mayor de Cuentas; GM. LR: Guerra y Marina, libro de Registro; BL: British Library (Londres); Add.: Additional; BPUG.CEF: Biblioteca Pública Universitaria de Ginebra. Col. Eduard Favre; CODOIN: Colección de Documentos inéditos para la Historia de España; IVDJ: Instituto Valencia de Don Juan (Madrid). 
otro, una sección horizontal que nos permitirá adentrarnos en el tipo de conexiones que se entablaban entre los diferentes criados e instituciones del monarca, ya fuera en la corte o en el territorio.

Palabras clave: Portugal. Azores. Corte. Patronazgo y clientelismo. Ejército.

\section{ORGANIZATION OF THE AZORES NAVAL CAMPAIGN OF 1582: COURT AND TERRITORIES IN THE REIGN OF PHILIP II}

ABSTRACT: This study is aimed at dealing with the exercise of royal power, its intermediation through the court and its projection on territories through an analysis of the organization of a specific military campaign, namely the Azores campaign of 1582, in greater depth. The common thread which belps us better understand this event is a closer examination of the leading figure and officer who took part: the field master Francisco de Bobadilla, future count of Puñonrostro. This analysis will allow us to establish the characteristics of two different types of relationship between the instruments of the sovereign's power, taken to be either receivers and distributors of his grace or as negotiators of his delegated jurisdiction. The key to achieving this objective is to perform a vertical study, following a line starting from the monarch himself and terminating at the final recipients of his orders, passing through the intermediate ministers and secretaries, as well as a horizontal cross-section of the court, which will allow us to comprehend the different connections between the different servants and institutions of the monarch, either at court or further afield in the king's territories.

KEY WORDS: Portugal. Azores. Court. Patron-client relationship. Army.

El día 13 de agosto de 1578 llegaba al Real Monasterio de San Lorenzo de El Escorial tres correos con la noticia de la derrota de don Sebastián en la batalla de Alcazarquivir ocurrida el 4 de dicho mes. Cuatro días más tarde se confirmaba de manera oficial la luctuosa noticia mediante una carta del embajador portugués don Fernando da Silva al secretario Zayas ${ }^{1}$. Se abrió entonces un periodo: «la crisis dinástica», que sólo se cerraría con el juramento que Felipe II prestó ante sus nuevos súbditos portugueses en las Cortes reunidas en la villa de Tomar, que se conoce con el nombre de «Sucesión Portuguesa»².

${ }^{1}$ El 10 o el 11 de agosto comenzaron a llegar a Lisboa las primeras referencias de la derrota de Alcazarquivir, aunque la confirmación oficial llegó un poco más tarde, el día 24, a través de las cartas que envió Belchior de Amaral, corregidor de la corte, que se encontraba en Tánger. Velloso, José María de Queirós, A perda da Independencia. Vol. I. O reinado do Cardeal D. Henrique, Lisboa, Empresa Nacional de Publicidade, 1946, págs. 6-11. Así como FERNÁndeZ ConTI, Santiago, «La Junta Militar de Portugal, 1578-1580», en: Martínez Millán, José, Fernández Albaladejo, Pablo y PINTO CReSPO, Virgilio (coords.), Política, religión e Inquisición en la España Moderna, Madrid, UAM, 1996, págs. 287-291.

2 Al respecto, Bouza Álvarez, Fernando, Portugal en la Monarquía Hispánica (1580-1640). Felipe II, las Cortes de Tomar y la génesis del Portugal Católico, 2 vols., Madrid, Universidad Complutense, 1987 (tesis doctoral inédita) y VeIGA, Carlos Margaça, Poder e poderes na crise sucessória portuguesa (1578-1581), 2 vols., Lisboa, Universidad de Lisboa, 1999 (tesis doctoral inédita). 
Felipe II era un candidato más, compartía sus opciones con la reina de Francia, con Catalina, duquesa de Braganza, con Manuel Filiberto de Saboya, con don Antonio, prior de Crato, y con Rainuccio de Parma, pero que tenía a su favor unos sólidos argumentos jurídicos, el placet de la gran mayoría de la hidalguía portuguesa, un poderoso ejército y el buen hacer de sus delegados en el reino portugués ${ }^{3}$. Sin embargo, a pesar de los sólidos argumentos que sustentaban la causa filipina, la unión con la Corona de Portugal quedaría, finalmente, en manos portuguesas, triunfando, en este sentido, la denominada opción lusitana ${ }^{4}$. Portugal se incorporaría a la Monarquía Hispana por el deseo que manifestaron la gran mayoría de sus elites dirigentes: nobleza, alto clero y elites urbana, que veían en la unión con la Monarquía Hispana la única manera de mantener el sistema que había articulado e integrado el reino desde al menos finales del siglo XIII: es decir la corte y la casa real's. No obstante, el pueblo llano, alentado por el bajo clero y por las órdenes religiosas, apoyó al prior de Crato, autoproclamado rey de Portugal en las Cortes de Almeirim, el 18 de junio de 1580, lo que obligó a Felipe II a utilizar al ejército que tan cuidadosamente habían estado preparando el duque de Alba y el marqués de Santa

3 Pereña Vicente, Luciano, «El arbitraje internacional y la conquista de Portugal», Revista Española de Derecho Internacional, 8, 1-2 (1955), págs. 105-165; BorromeO, Agostino, «La Santa Sede y la candidatura de Felipe II al trono de Portugal», en Congreso Internacional las Sociedades Ibéricas y el mar a finales del siglo XVI. T. V. El área Atlántica. Portugal y Flandes, Madrid, Sociedad Estatal Lisboa 98, 1998, págs. 41-58; GonZÁlez CruZ, David, «Arias Montano y la fundamentación de los derechos de Felipe II al trono de Portugal», en: Gómez Cansado, Luis (ed.), Anatomía del humanismo. Benito Arias Montano, 1598-1998, Huelva, Universidad de Huelva, 1998, págs. 301-318; DenunZiO, Antonio Ernesto, «Strategie diplomatiche e vicende dinastiche: le pretese dei Farnese nella successione al trono di Portogallo (1578-1580)», en: BerTini, Giussepe (ed.), María di Portogallo sposa di Alessandro Farnese. Principessa di Parma e Piacenza dal 1565 al 1577, Parma, Ducati, 2001, págs. 224-258; RuMEU DE ARMAS, Antonio, «Los derechos de Felipe II al trono y conquista de Portugal según los teólogos españoles», Universidad, 17 (1940), págs. 27-45; CuNHA, Mafalda Soares da, «A questão jurídica na crise dinástica», en: MAgalHÃes, Joaquim Romero (coord.), No Alvorecer da Modernidade (14801620), Lisboa, Círculo de Leitores, 1993, vol. III, págs. 552-559 y LABRADOR ARROYO, Félix, La Casa Real Portuguesa de Felipe II y Felipe III: la articulación del reino a través de la integración de las élites de poder (1580-1621), Madrid, UAM, 2007, cap. 1.

4 VeIga, Carlos Margaça, A agregação da Coroa de Portugal à de Castela. Aspectos da Estratégia de Filipe I, Lisboa, Universidade de Lisboa, 1990.

5 LABRADOR ARroyo, Félix, «La casa real portuguesa en tiempos de Felipe II (1581-1598)», en: Martínez Millán, José y Fernández ConTi, Santiago (dirs.), La Monarquía de Felipe II: la Casa del rey, Madrid, Fundación Mapfre-Tavera, 2005, vol. I, págs. 801-945, esp. 883-908. Sobre el papel de la corte durante la edad Moderna véanse, fundamentalmente, los trabajos de MARTínEZ Millán, José, «Introducción», en: La Monarquía de Felipe II..., vol. I, págs. 17-52; y «La corte de la Monarquía Hispánica», Stvdia Histórica. Historia Moderna, 28 (2006), págs. 17-61, así como ÁlvareZ-Ossorio AlvariÑo, Antonio, «La Corte: un espacio abierto para la Historia Social», en: Castillo, Santiago (coord.), La Historia Social en España. Actualidad y perspectivas, Madrid, Siglo XXI, 1991, págs. 235-256 y «Las esferas de la Corte: príncipe, nobleza y mudanza en la jerarquía de la Monarquía de España», Annali di Storia Moderna e Contemporanea, 8 (2002), págs. 47-111. 
Cruz ${ }^{6}$. Como señaló el conde de Salinas, don Diego de Silva y Mendoza: «la forma en que se unió esta Corona [Portugal] con la de Castilla tuvo de herencia, de conquista y de compra» ${ }^{7}$.

En este contexto general, nuestro propósito es profundizar en el ejercicio del poder real, su mediatización cortesana y su proyección sobre el territorio en una de sus vertientes más sobresalientes en la época moderna. Para ello, en nuestra opinión, uno de los mejores campos de estudio entre los variados escenarios militares posibles es la organización de una campaña concreta, porque su análisis permite establecer las características de dos formas diferentes de relación entre los instrumentos de poder del monarca tomados éstos bien como receptores y difusores de su gracia, bien como gestores de su jurisdicción delegada en mayor o menor grado; por un lado, se trata de realizar un análisis vertical, en una línea que tiene su punto superior en el monarca y concluye en los destinatarios últimos de sus órdenes - en este caso, el maestre de campo de un tercio y los distintos oficiales administrativos-, y pasa por la posición intermedia de ministros, secretarios y organismos; por otro, un corte horizontal nos ha de permitir escudriñar en el tipo de conexiones que se entablaban entre los diferentes criados e instituciones del monarca, ya fuera en la corte o en el territorio ${ }^{8}$.

El ejemplo escogido para este propósito es la empresa naval de las Azores de 1582, cuando Felipe II, con gran parte de su corte, se hallaba todavía en

${ }^{6} \mathrm{Al}$ respecto, véase el reciente trabajo de VALladAres, Rafael, La conquista de Lisboa. Violencia militar y comunidad política en Portugal, 1578-1583, Madrid, Marcial Pons, 2008, así como los clásicos estudios de Estébanez Calderón, Serafín, De la conquista y pérdida de Portugal, 2 vols., Madrid, Imprenta de A. Pérez Dubrull, 1885 y SuÁREZ InCLán, Julián, Guerra de anexión en Portugal durante el reinado de Felipe II, 2 vols., Madrid, Imp. y Lit. del Depósito de la Guerra, 18971898. Sobre el gobierno del prior puede verse SERRÃo, Joaquim Veríssimo, O reinado de D. António, Prior do Crato (1580-1582), Coimbra, Universidade, 1946.

7 Cit. Bouza Álvarez, Fernando, Portugal en la Monarquía Hispánica..., vol. I, págs. 221222. Véanse del mismo autor algunos de sus trabajos recogidos en: Portugal no tempo dos Filipes. Política, Cultura, Representaçoes (1580-1668), Lisboa, Cosmos, 2000.

${ }^{8}$ No es la primera vez que se plantean estudios similares, destacamos, para no ser exhaustivos, los estudios de Quatrefages, René, Los Tercios, Madrid, FUE, 1979 y La Revolución militar moderna. El crisol español, Madrid, Ministerio de Defensa, 1996; THOMPSON, Irving A.A., Guerra y decadencia. Gobierno y administración en la España de los Austrias, 1560-1620, Barcelona, Crítica, 1981; Gracia Rivas, Manuel, Los Tercios de la Gran Armada (1587-1588), Madrid, Naval, 1989 y La invasión de Aragón en 1591: una solución militar a las alteraciones del Reino, Zaragoza, Diputación de Zaragoza, 1992; PARDo Molero, Juan Francisco, La defensa del Imperio. Carlos V, Valencia y el Mediterráneo, Madrid, Sociedad Estatal para la Conmemoración de los Centenarios de Felipe II y Carlos V, 2001; JimÉneZ EstrelLA, Antonio, Poder, ejército y gobierno en el siglo XVI. La Capitanía General del Reino de Granada y sus agentes, Granada, Universidad de Granada, 2004 y Los nervios de la Guerra. Estudios sobre el ejército de la Monarquía Hispánica (siglos XVI-XVIII): nuevas perspectivas, Madrid, Comares, 2007; así como los trabajos contenidos en el segundo volumen del reciente trabajo de García Hernán, Enrique y MAFFi, Davide (coords.), Guerra y sociedad en la Monarquía Hispánica: política, estrategia y cultura en la Europa Moderna (1500-1700), Madrid, Ediciones del Laberinto-Fundación Mapfre-CSIC, 2006, 2 vols. 
Lisboa. Operación victoriosa que, como preámbulo de la ocupación completa del archipiélago al año siguiente, fue aclamada por los cronistas de la época con distintos grados de intensidad ${ }^{9}$ y abordado por investigadores actuales ${ }^{10}$. El hilo conductor que nos sirve para adentrarnos en este episodio es la figura de uno de los principales oficiales que tomaron parte en el mismo, el maestre de campo don Francisco de Bobadilla, futuro conde de Puñonrostro ${ }^{11}$.

\section{EL CONTEXTO}

Durante el largo periodo de tiempo en el que Felipe II tuvo responsabilidades de gobierno, su forma de administrar el complejo patrimonio dinástico reunido por su padre conoció una evolución muy clara ${ }^{12}$. El norte del proceso, culminado no sin problemas durante los últimos años del reinado, fue la separación entre la esfera de acción política, copada en líneas generales por la nobleza, que actuaba en el entorno del monarca, y el ejercicio jurisdiccional y gubernativo, reservado para los órganos de la polisinodia, que alcanzaron entonces su conformación plena. Desde este punto de vista, el viaje a Portugal, casi tres años de corte itinerante, maduraron determinadas formulas en la corte

9 Mientras el auditor de la armada Mosquera De Figueroa, Cristóbal, Comentario en breve compendio de disciplina militar en que se escribe la jornada de las islas de las Azores, Madrid, Luis Sánchez, 1596, despacha la jornada de 1582 con un par de hojas (fols. 10v-12r), por el contrario HERRERA Y TORDesillas, Antonio, Cinco libros de Antonio de Herrera de la Historia de Portugal y conquista de las Islas de las Açores en los años de 1582 y 1583, Madrid, Pedro Madrigal, 1591, describe la campaña con gran minuciosidad (fols. 159 y 162 a 183). El reconocido historiador ochocentista FeRNÁnDEZ Duro, Cesáreo, La conquista de las Azores en 1583, Madrid, Sucesores de Rivadeneyra, 1866, incluye un amplio apéndice documental.

10 Pi CORRales, Magdalena de Pazzis, Felipe II y la lucha por el dominio del mar, Madrid, Editorial San Martín, 1989, págs. 219-230; MENEZES, Avelino de Freitas de, As Açores e o dominio filipino: 1580-1590, Angra do Heroismo, Instituto Histórico da Ilha Terceira, 1987 y «A projecção do arquipélago dos Açores na problemática hispano-portuguesa de 1580», en: CARABIAS TORRES, Ana (dir.), Las relaciones entre Portugal y Castilla en la época de los descubrimientos y la expansión colonial, Salamanca, Universidad de Salamanca, 1994; SERPA, Francis J., "Hispanic strategic enterprise in the Atlantic: the campaign for the Azores in the Sixteenth Century», Boletim do Instituto Historico de Ilha Terceira, 45, 2 (1987), págs. 1365-1382; SALGADO AlBA, Jesús, «La maniobra estratégica española en el Atlántico: la campaña de las Azores, siglo XVI», Boletim do Instituto Histórico da Ilha Terceira, 45, 1 (1987), págs. 31-54; y Cerezo MARTínEZ, Ricardo: «La campaña de la isla Terceira (1583)», Revista de Historia Naval, 1, 3 (1983), págs. 5-45.

${ }^{11}$ Sobre este personaje véase Fernández ConTI, Santiago y LABrador Arroyo, Félix, «Entre las Azores y Flandes. La invernada en Andalucía de un Tercio de infantería española (15831584)», en: VÁzQUez LeSMes, Rafael (coord.), Homenaje a Antonio Domínguez Ortiz, Córdoba, Real Academia de Córdoba, 2004, págs. 355-375.

12 Para la evolución general del reinado nos remitimos a Martínez Millán, José y De Carlos Morales, Carlos J. (dirs.), Felipe II: la configuración de la Monarquía Hispana, Salamanca, Junta de Castilla y León, 1998 y MARTínez Millán, José y Visceglia, Maria Antonietta, «Introducción», en: MARTíneZ MiLlán y Visceglia, M.A. (dirs.), La Monarquía de Felipe III: la Casa del Rey, Madrid, Fundación Mapfre, 2008, vol. I, págs. 25-117. 
y en el gobierno: las juntas, que tras el regreso a Castilla no tardarían en revelar su eficacia; también, fue el tiempo en que comenzaron a consolidar su posición aquellos personajes destinados a dominar la política cortesana en el último tramo del reinado.

Por otro lado, la campaña de Portugal, desde un punto de vista militar, no fue un éxito completo. La holgada victoria terrestre conseguida por el duque de Alba, no había tenido su correspondencia en el ámbito ultramarino ${ }^{13}$. En concreto, en el estratégico archipiélago de las Azores, únicamente la isla de San Miguel había manifestado su lealtad al Rey Prudente. Era un problema tanto más preocupante, cuanto que era una pieza esencial en el escenario de las comunicaciones con las Indias y un lugar desde donde ingleses y franceses podían presionar a la Monarquía. No es de extrañar, por tanto, que una de las prioridades de Felipe II, una vez coronado solemnemente en Tomar, en abril de 1581, fuera asegurarse el control de las islas, en especial de la más importante, conocida como la Tercera ${ }^{14}$, y capturar al prior don Antonio ${ }^{15}$.

\section{El gobierno de Portugal}

Cuando el monarca castellano abandonó Madrid para tomar posesión de su nuevo reino, la corte se recuperaba del que fue, probablemente, el periodo más virulento en términos faccionales de su reinado. La contienda entre «papistas» y «castellanistas» se había saldado con el arresto de Antonio Pérez y la caída en desgracia de sus principales aliados. En la medida en que Pérez era secretario de Estado, los cambios inmediatos tuvieron gran incidencia en éste ámbito, pero las modificaciones en curso eran de largo alcance, y sus primeros trazos fueron visibles en Portugal. Su sustituto, Juan de Idiáquez, reunió en su persona las dos secretarías de Estado - Norte e Italia- y comenzó a frecuentar el entorno del monarca. Por su parte, el veterano Juan Delgado, secretario de la Guerra desde 1571, se benefició del vacío y de la emergencia militar, y durante los primeros tiempos vivió los días más fructíferos de su carrera ${ }^{16}$.

13 Véase el reciente estudio de VALladARES, Rafael, La conquista de Lisboa..., págs. 139-153.

14 MARQUeS, Guida, «La dimension atlantique de l'opposition antonienne au pouvoir des Habsbourg et l'enjeu brésilien (1580-1640) », Anais de História de Além-Mar, 4 (2003), págs. 213-246.

15 En carta de 20 de abril de 1581 el rey manifestaba al duque de Alba su deseo por concluir el problema que le suponía la existencia del Prior: «(...) habréis podido entender cuan de veras deseo que se busque D. Antonio, pues de hallarle depende ya el entero sosiego de este reino, y cortar las malas intenciones de sus apasionados, y el ludio de los designios de franceses, que debajo de su cubierta querían hacer sus mangas como sabéis, y así os ruego y encargo mucho que, en recibiendo ésta, me aviséis de la forma y traza que os paresce que se puede dar para coger a don Antonio, y no espantarle, que esto es lo que yo querría, y lo que conviene al bien del negocio (...)», CODOIN, $\mathrm{t}$. XXXIV, Madrid, 1859, págs. 259-260.

16 Al respecto Martínez Millán, José, «Introducción», en: La corte de Felipe II, Madrid, Alianza Editorial, 1994, págs. 29-35. 
El escenario que vivieron ambos secretarios era cambiante. Mientras el cardenal Granvela se quedaba en Madrid al frente de la administración, con el Rey Prudente viajaron solo determinados miembros de su corte, entre los que se encontraba parte de su casa real y la mayor parte de los consejeros de Estado y Guerra. Primero en Badajoz y luego en Lisboa, Felipe II hubo de enfrentar nuevos retos y responsabilidades de gobierno, y para ello acudió a una fórmula que había empleado con profusión durante la década anterior: las juntas. La reunión de expertos en diferentes materias apareció como la solución idónea, no solo para agilizar los trámites de gobierno, sino también para integrar a los miembros más significativos de las elites portuguesas en el servicio de la monarquía.

Por otro lado, en la medida en que el monarca dependió de los integrantes de las juntas para el despacho de los asuntos, los más avisados supieron aprovechar perfectamente la situación para ganarse la confianza regia. Fue el caso de Rodrigo Vázquez de Arce quien, a la sombra de Mateo Vázquez, controló la Cámara; o del III conde de Chinchón, que se hacía rápidamente con el control de los negocios de la Corona de Aragón e Italia. También, como hemos señalado, se beneficiaron de esta coyuntura el secretario de la Guerra, Juan Delgado, y el secretario de Estado, Juan de Idiáquez. Por lo que toca a los negocios portugueses, sin duda el hombre de confianza era don Cristóbal de Moura, quien había acreditado su fidelidad y buen hacer en el largo y complejo proceso sucesorio y, en menor medida don Juan de Silva, conde de Portalegre, y don Jorge de Atáide ${ }^{17}$. En suma, en 1581, cuando comenzó a prepararse la empresa de las Azores, todos ellos intervinieron de una u otra forma en su gestión.

\section{El fracaso de 1581}

En la primavera de 1581 Felipe II reorganizaba el ejército que le había proporcionado el sometimiento del pueblo portugués. Después de una muestra general, el Consejo de Guerra propuso que las 35 banderas de Sancho Dávila, maestre de campo general, fueran reducidas a 13, completando las compañías con 250 hombres cada una; el asunto quedó pendiente de la opinión de Alba sobre la necesidad de levantar varios miles de hombres en Castilla, en cuyo caso tendrían preferencia de mando los capitanes reformados ${ }^{18}$. Al mismo tiempo, el Rey Prudente reflexionaba sobre la importancia de la isla Tercera: «que es la

17 Sobre estos personajes, EzQuerRa Revilla, Ignacio, «La distribución de la Gracia durante la anexión de Portugal: Rodrigo Vázquez de Arce (1578-1583)», en: Política, religión e Inquisición..., págs. 267-286; Fernández ConTI, Santiago, «La nobleza cortesana: don Diego de Cabrera y Bobadilla, tercer conde de Chinchón» y BouZa Álvarez, Fernando, «Corte es decepción. Don Juan de Silva, conde de Portalegre», en: Martínez Millán, José (dir.), La corte de Felipe II..., págs. 229270 y $451-499$ respectivamente.

18 AGS, GM, leg. 109, núms. 76 y 77, Delgado al rey, 19 y 22 de abril. 
principal de las de los Açores, y a donde está el puerto a donde vienen todas las armadas de las Indias de Castilla y Portugal, a estado siempre por don Antonio»; $y$, ante las amenazas externas, decidía el envío de una armada que se estaba preparando en Lisboa, aunque los objetivos en principio no estuvieran claros:

«(...) y dicen que es fuerte. Y agora ha venido un aviso de allá en que se dice que han embiado a Francia y Inglaterra por socorro. Y por ser de tanta importancia esta isa por lo de las armadas, aunque ido ya allá un caballero que yo he enviado por gobernador de aquellas islas, combendrá que vaya luego don Pedro de Valdés, y aunque se mire si sería bien que lleve más navíos y más gente y artillería (...)»19.

Por orden del monarca, Delgado abrió un debate entre los principales ministros sobre el alcance de la armada de Valdés. En el mismo intervinieron los portugueses, que deseaban organizar la escolta necesaria para los barcos que debían de llegar de las Indias. Todavía el 3 de junio, con la flota a punto de zarpar, dudaba el rey sobre la conveniencia de reforzarla con navíos lusos (circunstancia que debía ocultarse a los naturales del reino), para ser capaz de enfrentarse a cualquier amenaza externa y de evitar el envío de una armada específica para proteger los convoyes de Indias ${ }^{20}$. En todo caso, se resolvió que el objetivo primero, que no admitía dilación, era el refuerzo de la isla de San Miguel, en tanto que de inmediato se prepararía una segunda armada para enviar a la zona ${ }^{21}$.

Después de la partida de Valdés ${ }^{22}$, el análisis de la situación en la corte nos ilumina los diferentes ámbitos de consulta que manejaba el Rey Prudente ante

19 AGS, GM, leg. 109, núm. 83, Felipe II al secretario Delgado, 3 de mayo.

20 AGS, GM, leg. 109, núm. 99, 29 de mayo, el rey a Delgado, con el aviso de la llegada de amenazadoras noticias de Inglaterra; y núm. 102, 3 de junio, con amplias reflexiones del soberano. Parecer del marqués de Santa Cruz, AGS, GM, leg. 106, núm. 67.

21 PI CORRALES, Magdalena de Pazzis, Felipe II y la lucha por el dominio del mar..., págs. 217-218.

22 Copia de dos capítulos de la instrucción que se dio a don Pedro de Valdés: «Y llegadas las naos de la India Oriental, que siempre suele ser antes que las occidentales, o quando os paresçiere combenir según tuvieredes los avisos, pasareis adelante no sólo de la Isla Terçera, pero de todas las Islas de los Açores por la derrota que an de venir para asegurar y limpiar aquella Carrera de corsarios y advertir a las flotas que vinieren de las Occidentales del estado que tuviere lo de la isla Terçera, embiando ansimismo a encontrarlas si os paresçiere çien leguas antes alguna caravela con los avisos que combiniere darles, porque en caso que la Isla Terçera no estuviese a la saçón en nuestra ovediençia no vayan a tomar puerto en ella por el incombiniente que desto les podría subçeder y sigan y vayan por su derrota derecha a entrar en Sanlucar de Barrameda como lo acostumbrarn hazer. Y demás dello, quando vieredes que es tiempo de venir la dicha armada de la India y las otras de Tierra Firme y Nueva España yréis a pasar como esta dicho con la dicha armada todas las Islas a encontrarlas para que no estando la Isla Terçera a nuestra devoçión y servicio las podáis avisar que no toquen ni entren en ella y de donde las topareredes encaminareis la armada de la India a Lisboa y las de Tierra Firme y Nueva España a Sanlucar, procurando de venir asegurando las unas y las otras hasta ponerlas en salvo y seguridad, según vieredes combenir y os paresçiere, adviertiendo que siempre viene muy más temprano la de la India y que en este caso avéis de procurar de encaminarla y asegurarla y desde donde vieredes que lo está bolver a hazer lo mismo a 
un escenario bélico y el uso discrecional que hacía de cada uno de ellos: Consejo de Estado, Consejo de Guerra, juntas y consultas por separado a los ministros (en especial, al duque de Alba para las tropas terrestres y al marqués de Santa Cruz para las navales), con el secretario Delgado como imprescindible correa de transmisión - siempre dispuesto a aportar sus propias opiniones sobre los procedimientos a emplear - y el concurso de mandos y oficiales de un segundo nivel, como Francés de Álava (consejero de Guerra y capitán general de la artillería) y Andrés de Alva (proveedor general).

De este modo, hacia el 20 de junio de 1581, el rey ordenaba a Delgado juntar al duque de Alba, con el marqués de Santa Cruz y Francés de Álava, a fin de revisar una consulta del Consejo de Estado sobre las noticias que llegaban de las Azores ${ }^{23}$. Días más tarde, mandaba al secretario de la Guerra se entrevistase en privado con Santa Cruz, a fin de comentarle varios asuntos preocupantes $^{24}$. Las amenazantes noticias de Inglaterra llevaron a Bazán a recomendar el envío de cuatro naos de vigilancia a las costas gallegas, consejo aceptado por el monarca; además, Santa Cruz disipó los temores regios acerca de las posibilidades que tenía la flota de Valdés de resistir con éxito a los más de treinta navíos franceses, que se sospechaba se dirigían a la Tercera.

Con todo, la materia más importante que trataron ambos fue el ofrecimiento que hizo Delgado al almirante para que dirigiese la segunda flota que había de enviarse a la Tercera, con autoridad sobre todas las tropas terrestres y marítimas, incluidas las naves de Valdés. La decisión de tantear el interés del marqués fue discutida entre Delgado y Cristóbal de Moura y, a su vez, en el Consejo de Estado que permanecía al lado del monarca ${ }^{25}$. El objetivo evidente, reconocido por Felipe II en su contestación a Delgado, era asaltar la isla más importante del archipiélago, decisión que justificaba por la necesidad de evitar su fortificación, que en el próximo verano de 1582 haría la operación mucho más complicada. Como sucediera tres años antes, con la preparación de la conquista de Portugal, Felipe II manifestaba su preferencia por una campaña rápida, que sorprendiera al enemigo ${ }^{26}$. Sin embargo, el marqués excusó el ofreci-

las de Tierra Firme y Nueva España y si por caso viniesen todas juntas lo qual es de creer que no arán usareis en encaminarlas y asegurarlas cada una a la parte que a de venir de lo que os paresçiere combenir trayendo junta esa armada, adviertiéndola para asegurarlas según lo que más combiniere y que todo venga con recaudo y no les pueda subçeder incombiniente ni resçivir ningún daño de cosarios a que se a de tener el principal fin como cosa de que redundaría tanto incombiniente con qualquier navío que lo Dios no permita tomasen de las dichas armadas pues para obiarlo y asegurarlo vais con la dicha armada». AGS, GM, leg. 109, núm. 407.

${ }_{23}$ AGS, GM, leg. 109, núms. 116 y 117, la orden del rey a Delgado, 19 de junio. Los puntos a tratar en núm. 115.

${ }^{24}$ AGS, GM, leg. 109, núm. 119.

25 AGS, GM, leg. 109, núm. 121, Felipe II a Juan Delgado, 23 de junio.

26 A este respecto véase Fernández Conti, Santiago, «La Junta Militar de Portugal, 15781580», en: Martínez Millan, Fernández Albaladejo y Pinto Crespo (coords.), Política, religión e Inquisición..., págs. 287-308. 
miento con el argumento de que las posibilidades de éxito de la empresa eran escasas, dado lo avanzado de las fechas y la falta de preparación adecuada. En su opinión, ambas flotas debían asegurar, sobretodo, el tráfico de Indias y, si había ocasión, desembarcar tropas en tierra, para cuyo propósito se bastaba el maestre de campo Lope de Figueroa. En resumen, que «(...) ir él para solo esto y bolberse antes sería perder reputación», aunque se ofrecía para dirigir la jornada la temporada siguiente ${ }^{27}$.

Descartado el marqués de Santa Cruz, se pensó entonces en el catalán Galcerán de Fenollet, con la condición de que en aquellas aguas había de quedar bajo la autoridad del propio Valdés. Pero don Galcerán hacía tiempo que en Consejo de Guerra advirtiera su poca disposición a quedar bajo la autoridad de nadie, al tiempo que recordaba el acuerdo previo tomado con Lope de Figueroa y Delgado, refrendado en la posada del duque de Alba, sobre las características que había de reunir la armada ${ }^{28}$. También Lope de Figueroa se mostró muy renuente a participar en la expedición, al considerar complicado el cumplimiento de los objetivos, si bien el duque de Alba estaba convencido de la calidad de la infantería puesta a su disposición ${ }^{29}$. A la postre, mientras Delgado se ocupó de convencer a Figueroa, en el caso del catalán don Galcerán parece que resultó determinante la mediación del hombre fuerte en los temas de la Corona de Aragón, el conde de Chinchón ${ }^{30}$. Y no fueron las únicas dificultades que hubo de afrontar el secretario de Guerra. A su entender, el mando supremo del achacoso duque de Alba de las fuerzas de tierra ralentizaba las operaciones; ante sus quejas, Felipe II, que reconocía el problema mas no deseaba desautorizar abiertamente al general, ordenó que Bazán y Francés de Álava, y los oficiales que fuesen necesarios, se reuniesen con él mismo para coordinar las operaciones de todo tipo necesarias para concluir el despacho de la armada ${ }^{31}$. Finalmente, la armada de don Galcerán zarpó el 25 de julio, día elegido por don Pedro de Valdés para, por su cuenta y riesgo, intentar la ocupación de la Tercera. El desastre subsiguiente provocó un disgusto mayúsculo en el monarca y sus ministros, pues la trascendencia del objetivo —Delgado había llegado a escribir que «(...) aquello que van ha hazer es de tanta ynportancia que no conviene herrarlo la primera ${ }^{32}$ - mal sufría la desobediencia de los oficiales.

El fracaso de 1581 obligó al gobierno de Felipe II a diseñar una política defensiva de aplicación inmediata, a fin de conjurar las posibles amenazas. La

27 AGS, GM, leg. 109, núm. 119.

${ }_{28}$ AGS, GM, leg. 109, núm. 125, carta de don Galcerán al rey, 26 de junio de 1581.

29 AGS, GM, leg. 109, núms. 122, 130 y 140.

30 AGS, GM, leg. 109, núm. 123, 26 de junio, contestación de Felipe II a una relación de Juan Delgado: «y creo que el conde de Chinchón será buen medio para hacerle venir [a don Galcerán] en lo que se quisiere». Surtió efecto, pues al día siguiente don Galcerán trataba ya aspectos de su título e instrucción con el marqués de Santa Cruz. AGS, GM, leg. 109, núm. 127.

31 AGS, GM, leg. 109, núms. 124 y 126, Delgado al rey, con contestación de 25 y 27 de junio.

32 AGS, GM, leg. 109, núm. 130. 
cuestión que más preocupaba, como es lógico, era la seguridad de las Indias, castellanas y portuguesas. Para ello, entre finales de agosto y principios de septiembre, el rey ordenó un sistema de juntas, cuyo núcleo medular estaba formado por Juan Delgado, Antonio de Eraso y Juan Núñez de Illescas (con acceso a la información más reservada) a los que se agregaban si era necesario Juan de Idiáquez y los portugueses Cristóbal de Moura, Luís Cesar, Miguel de Moura y Pedro de Alçacoba Carneiro ${ }^{33}$. Esta Junta supervisó los pareceres sobre el tema pedidos a mediados de octubre al Consejo de Indias en Madrid y a la Casa de Contratación de Sevilla, incluida la opinión del duque de Alba sobre los mismos, hasta alcanzar unas conclusiones, que fueron consultadas al monarca el 17 de diciembre. Semanas después, el veinte de enero de 1582, se promulgó las nuevas ordenanzas para el despacho de las flotas de Indias y su seguridad ${ }^{34}$. También se juntaron por estos días, a caballo entre el verano y el otoño de 1581, el duque de Alba y Cristóbal de Moura, con el encargo de tratar del refuerzo de la isla de Madeira, aunque recomendaron se instruyese por la vía del Consejo de Portugal. Felipe II estuvo de acuerdo pues «(...) importa mucho asegurar esto y el Brasil, ya que no se ha hecho lo de la Tercera» ${ }^{35}$. Para proteger Madeira se enviaron dos galeones con la infantería que había formado parte de la expedición de Valdés, detenido en el momento de su entrada en el puerto de Lisboa, el 25 de septiembre, mientras que los capitanes y oficiales fueron reformados ${ }^{36}$.

Aparte de atender a la seguridad oceánica, en la corte de Lisboa se consideró la necesidad de realizar nuevas levas y movimientos de tropas, que permitieran afrontar las cuestiones más inmediatas. En el mes de agosto, Felipe II ordenó el traslado a la península de mil quinientos hombres de los acantonados en Milán y nombró dos nuevos maestres de campo: Luis Enríquez y Antonio Moreno, con 11 y 17 capitanes respectivamente, que habrían de reclutar hombres en Tierra de Campos y en Andalucía; asimismo, se despacharon otros diez capitanes a levantar gente en diferentes zonas de Castilla ${ }^{37}$. Mientras la unidad

33 AGS, GM, leg. 109, núms. 227 y 228, relaciones de Delgado y Eraso al rey sobre lo tratado en la junta; además, AGS, GM, leg. 109, núm. 452, relaciones de Eraso de las dos versiones de la junta. núm. 41.

34 AGS, GM, leg. 109, núm. 404, copias de las mismas en leg. 122, núm. 269 y leg. 175,

35 AGS, GM, leg. 109, núm. 262, 25 de septiembre de 1581.

36 AGS, GM, leg. 109, núms. 264, 273 y 283.

37 AGS, GM, leg. 117, núm. 174, leg. 118, núm. 141. Los títulos de los maestres de campo, el 27 de agosto de 1581, en AGS, GM. LR, 36, fol. 345; se nombraron también los sargentos mayores del tercio. Respecto a los diez capitanes, el 26 de agosto se dio orden de pago de 30 ducados por persona; como veremos más adelante, estos capitanes acabaron por encuadrarse en el tercio de Francisco de Bobadilla; su procedencia era diversa: por ejemplo, Funes y Castilblanco salieron de las tropas de Sancho de Ávila en el norte de Portugal (GM, leg. 117, núm. 88). Antonio Moreno, un anciano de 64 años, posaba en Baeza cuando recibió la orden, que acató con la consabida petición de merced (GM, leg. 117, núm. 197). 
de Enríquez estaba en principio destinada a asegurar la zona norte de Portugal contra una posible amenaza francesa, las banderas de Moreno estaban pensadas para ponerse a las órdenes del duque de Medina Sidonia en la jornada de Larache. (Durante los meses siguientes, la maduración de una estrategia en la corte para la próxima campaña, en función de unas determinadas prioridades, tuvo su repercusión directa sobre el movimiento de las unidades en el territorio).

\section{LA ORGANIZACIÓN DE LA NUEVA CAMPAÑA}

La derrota de Valdés abrió una larga discusión en la corte sobre las posibilidades de asalto de la isla rebelde. Al decir de un cronista $^{38}$, unos ministros eran partidarios de la fortificación de San Miguel, a la espera de que la estrangulación del comercio terminase con los defensores del resto de las islas, dadas las grandes dificultades existentes para la acometida; otros, por el contrario, defendían un nuevo asalto en 1582, no solo para mantener intacta la reputación del monarca, sino porque sin duda los franceses se harían fuertes y terminarían por ocupar San Miguel y Madeira. A este respecto, los avisos amenazantes se sucedieron durante el otoño de $1581^{39}$. Todavía a principios de noviembre Felipe II dudaba sobre la oportunidad de llevar a cabo la empresa de la Tercera, como revelaba en un comentario a Delgado:

«También será menester myrar lo que se hará de la infantería que viene de Italia, que si no fuese menester para lo de la $3^{\text {a }}$ bien se podría bolber, y si aquella se ha de hazer menester es gente práctica como aquella»40.

La reflexión del monarca contiene un elemento fundamental de la elaboración de cualquier estrategia, como era la determinación previa de los objetivos como premisa básica para el movimiento de las fuerzas militares disponibles. En aquellas semanas de otoño, en la mente de Felipe II, se barajaban dos acciones a realizar en la zona del Atlántico durante 1582, complementarias entre sí, en la medida en que ambas pretendían la seguridad de la navegación indiana, pero que por su evidente desigualdad no entraron en competencia por los recursos de la Monarquía. La más limitada era la ocupación de la plaza de Larache, plaza africana que desde hacia varios años venía siendo prometida al rey por el Xarife de Marruecos en señal de amistad ${ }^{41}$.

38 Herrera y Tordesillas, Antonio, Cinco libros..., pág. 159.

39 Por ejemplo, AGS, GM, leg. 109, núm. 283.

${ }^{40}$ AGS, GM, leg. 109, núm. 318, Delgado a Felipe II, con contestación al margen, 8 de noviembre de 1581. Más información en VALLADARES, Rafael, La conquista de Portugal..., págs. 139-144.

${ }^{41}$ Sobre el negocio de Larache, Cabanelas RodrígueZ, Darío, «El problema de Larache en tiempos de Felipe II», Miscelánea de Estudios árabes y hebraicos, 9 (1960), págs. 19-53 y FerNÁNDEZ CONTI, «La Junta Militar de Portugal...», págs. 287-308. La empresa de Larache, aunque a la 
El segundo objetivo meditado por el rey para 1582 era, como prevenía a Delgado, el asalto de las Azores. En algún momento después del mes de agosto, el monarca pidió a Delgado la elaboración de un estudio sobre el coste que supondría una fuerza de ocho mil hombres durante seis meses. El minucioso análisis, presentado al rey en Lisboa el 19 de octubre, incluía el empleo de la empresa de tres tercios, con trece banderas cada $u_{n o}{ }^{42}$, pero Felipe II se tomó su tiempo para pensarlo. Y, dado que avanzaba el otoño, en el ínterin ordenó tanto la suspensión de la leva del tercio de don Luis Enríquez ${ }^{43}$ como el estudio de los posibles objetivos de la infantería proveniente de Italia. El Consejo de Guerra recomendó el regreso de las galeras a sus bases, previo desembarco del tercio de Milán en Orán (de cuyo mando se debía dar posesión a Lope de Figueroa), lugar del que en cualquier caso podría traerse rápidamente si fuera necesario; asimismo, la gente más escogida del tercio de Moreno debía henchir los de Italia, mientras que el tercio de Luis Enríquez, cuya recluta había sido paralizada, debía despedirse, siempre y cuando sus capitanes quedaran localizados por si hubiere necesidad y con alguna forma de entretenimiento. El hecho de que el monarca dilatase el negocio, pretextando debía consultarse con el duque de Alba, no hacía sino reflejar las dudas en las que se hallaba sumido ${ }^{44}$.

\section{Decisiones en la corte}

Felipe II tomó su decisión sobre la Tercera probablemente a mediados de noviembre de 1581, acuciado por las noticias que llegaban sobre el movimiento de naos francesas en el archipiélago. Tras repensar las estimaciones elaboradas por Delgado, autorizó el levantamiento de la armada, con los ocho mil hombres previstos de infantería ${ }^{45}$. Pero la nefasta experiencia del verano y la conciencia de las amenazas exteriores, llevaron al Rey Prudente a concluir que tan eficaz como el asalto militar podía resultar el diseño de una campaña previa de intimidación:

«una de las cosas que se pretende desta armada para la $3^{\text {a }}$ es que haga mucho escándalo y las prevenciones sean tantas y de manera que las teman, porque po-

postre no se llevó a cabo, tuvo una virtud añadida para el monarca y sus ministros, como fue el convertirse en destino perfecto para apartar al personal no deseado de tareas importantes.

42 AGS, GM, leg. 119, núm. 229.

43 AGS, GM, leg. 118, núm. 145, Enríquez al rey, con notificación de la necesidad que pasaban los oficiales del tercio tras la suspensión de la leva y la falta de dinero, 31 de octubre.

${ }_{4}$ AGS, GM, leg. 109, núm. 321, Delgado al rey, con contestación, 19 de noviembre de 1581.

45 AGS, GM, leg. 109, núm. 534, Felipe II en contestación a Delgado, sin fecha: «He visto la relación de lo de la armada y paréceme que se haga y prevenga todo para ocho mil hombres, que bien serán menester que vayan y bien cumplidos por muchas cosas que se pueden ofrecer de aquí allá. Y después se verá que gente será, y mírese en que partes se hará todo, que en quantas más fuere se hará más presto y mejor». 
dría ser que con esto se viniesen a reducir (...) Y solo lo del Andalucía, como es tan lexos de Francia y Inglaterra, no sonará tanto como lo que se hiziese en esotra costa de la mar de poniente, desde Galicia a Guipúzcoa. Y en verdad que cosas se podrían ofrecer y aun temerse que no fuese malo tener allí prevenida otra buena armada (...)»,

y continuaba ordenando estudiar el asunto en Consejo de Guerra, pues «quanto más ruido se haga y más prevençión y en más partes, será lo mejor» ${ }^{46}$.

El secretario de la Guerra, siempre presto a ofrecer los conocimientos proporcionados por su luenga experiencia en la administración, recordó al monarca un procedimiento empleado años ha «(...) sobre la prevención para el ruydo». Consistía en pagar pífanos y tambores a los capitanes entretenidos en Castilla para tocar bandera, aunque no se asentasen soldados; según Delgado, el alboroto había sido suficiente, con un coste reducido, para aquietar a los franceses mientras Felipe celebraba Cortes en Monzón ${ }^{47}$. En la misma línea, a finales de noviembre, el Consejo de Guerra recomendó de nuevo que el tercio de Luis Enríquez y cinco capitanes de Extremadura «(...) no desarbolen bandera ni levanten gente, hasta que otra se les ordene»; y respecto al tercio de Moreno (que tenía seis compañías destinadas a la empresa de Larache) se propuso elegir otra media docena de capitanes para despachar al maestre de campo, listos para hacer gente cuando fuera preciso. Todas las sugerencias fueron aprobadas por el rey, incluida la consulta anterior del Consejo, de enviar a Orán el revoltoso tercio de Lope de Figueroa, en cuanto desembarcara en Cartagena, cosa que hizo los últimos días de diciembre ${ }^{48}$.

Al tiempo que planteaba la campaña de propaganda, la primera preocupación del rey a la hora de levantar armada y ejército era la cuestión logística, es decir, reunir el dinero y las provisiones suficientes para pagar y mantener al contingente militar previsto. La figura encargada de coordinar las operaciones de abastecimiento era el proveedor general de armadas y fronteras en Andalucía, oficio de suma importancia que por aquel entonces ejercía Francisco Duarte. El problema era que Duarte, hijo del que fuera proveedor general en tiempos de Carlos V, se hallaba bajo sospecha. Factor de la Casa de la Contratación de Sevilla, una investigación iniciada en 1577 por el consejero Benito López de Gamboa le había obligado, en 1580, a dejar el cargo en manos de su hijo, del mismo nombre, durante dos años ${ }^{49}$. Desde entonces arreciaban los ataques hacia su persona, hasta el punto de que en septiembre de 1581 fue elegido para asistir al duque de Medina Sidonia en Gibraltar en la preparación de la empresa de Larache, maniobra que no buscaba otra cosa que alejarle de Sevilla y

46 AGS, GM, leg. 109, núm. 336, el rey a Delgado, 24 de noviembre de 1581.

47 AGS, GM, leg. 109, núm. 337, Delgado al monarca, 26 de noviembre.

48 AGS, GM, leg. 109, núm. 333, Delgado a Felipe II, 20 de noviembre de 1581.

49 AGS, GM, leg. 119, núm. 32, copia de cédula de 20 de junio de 1580, por el que se autorizaba el ejercicio del oficio al hijo de Duarte. 
apartarle del cargo, de cuya gestión diaria se encargó a Jorge Manrique ${ }^{50}$. Duarte se defendió con energía y, avezado conocedor de las normas cortesanas, además de dilatar varias semanas su partida, acudió a la mediación de un valedor, en este caso Juan Delgado, para obtener el oficio de proveedor general, con entrada en los Consejos de Hacienda y Guerra cuando estuviere en Madrid $^{51}$. Pero no escogió, si es que pudo hacerlo, la mejor baza. Porque, efectivamente, la búsqueda de su sustituto - en tanto duraran las pesquisas sobre su persona- fue objeto de las rivalidades cortesanas, encarnadas en dos secretarios de fuerte presencia en el manejo de los negocios: por un lado, el secretario de Guerra, Juan Delgado, y, por otro, Mateo Vázquez y su deudo, el consejero Juan Núñez de Illescas.

Decidido el alejamiento de Duarte de Sevilla, Mateo Vázquez y Juan Núñez de Illescas, por orden del rey, se reunieron a finales de septiembre para estudiar el futuro inmediato del cargo, que se presumía vital para la organización de las próximas campañas ${ }^{52}$. Propusieron diversificar en lo posible las áreas de gestión (Málaga y Cartagena) y, en todo caso, con el fin de cubrir el hueco de Duarte, mandar a aquella ciudad bien al reputado proveedor Andrés de Alva, bien a Antonio de Guevara, a cargo en aquellos momentos del almojarifazgo mayor de Indias. Como se demostró a la postre, Alva era el candidato de Vázquez, mientras que la idoneidad de Guevara era defendida por Juan Núñez - acaso por su continuado contacto en Sevilla_, quien por otro lado manifestaba una particular inquina hacia Duarte, situación denunciada por el interesado. En su respuesta, Felipe II expresaba su deseo de no prescindir de Alva en Lisboa, pero al mismo tiempo dudaba de la capacidad de Guevara para ocuparse de negocio tan arduo, pues anunciaba, aun sin citarla expresamente, que para la inminente campaña de la Tercera, «(...) es menester proveerse de manera que no haya la menor falta porque sería mal negocio si la hubiere, aviendo tanto que proveer y en cosas que importan tanto, que sería terrible negocio aver en ellas la menor falta del mundo». Sin agradarle, por tanto, ninguno de los candidatos, barajaba el monarca el nombre de Juan de Isunza, que había servido en Flandes.

Desconocedor de la existencia de estos tratos, unos días más tarde Juan Delgado, como secretario que era de la Guerra, inició los procedimientos acostumbrados para levantar armada en Andalucía, y presentó a la firma del monarca los documentos necesarios para encargar a Duarte su aprovisionamiento.

50 AGS, GM, leg. 118, núm. 85, Duarte al rey, dando cuenta de su llegada a Gibraltar el día anterior, 24 de octubre.

${ }^{51}$ AGS, GM, leg. 118, núm. 84, Duarte a Delgado, 16 de octubre. Pedía el oficio de proveedor general, que antes habían disfrutado su padre y Francisco de Ibarra, así como el título en propiedad de factor de la Casa de Contratación para su hijo. Repitió la petición al secretario el 21 de noviembre. AGS, GM, leg. 119, núm. 24.

52 IVDJ. Envío 55, caja 72, fol. 76, relación de lo acordado, de mano de Mateo Vázquez, a 24 de septiembre de 1581 . 
Desde este momento, Felipe II decidió que las relaciones de Delgado sobre el tema habrían de ser revisadas para su contestación por Mateo Vázquez y Juan Núñez. Ignoramos si Delgado fue consciente de la existencia de un canal paralelo de consulta - aunque es de suponer que su larga experiencia así se lo dictaría-, pero pronto se percató de la nula predisposición del monarca para contar con Duarte. En estas circunstancias, una vez decidida la ejecución de la empresa, a las pocas semanas, Delgado consideró que debía abordar directamente el negocio para presentar sus propios candidatos. Ya que no era factible acudir a Duarte - discurría Delgado- la persona con un perfil más adecuado era, sin duda, don Cristóbal de Barros, proveedor que había servido bien en Galicia y se ocupaba por aquel entonces de allegar naos para la empresa. Pero, una vez más, el rey trasladó la recomendación de Delgado a consulta de Vázquez y Núñez, y añadía la posibilidad de enviar a Sevilla a Alva y a Guevara. Ambos personajes, con el fin de diluir la responsabilidad en un espacio más amplio, sugirieron se ordenase al secretario de la Guerra el estudio por parte de la Junta de Santo Domingo («por tocar esto tanto en hacienda») de varios nombres (Arévalo de Cuaço, don Jorge Manrique, Luis Osorio y don Pedro de Guzmán) con el añadido final de Antonio de Guevara, que tenía la virtud de hallarse ya en Sevilla, con el consiguiente ahorro de tiempo ${ }^{53}$.

Aunque Andrés de Alva, la opción de Mateo Vázquez, había sido desechado por el monarca en su orden de consulta, el secretario luchó hasta el final por la nominación. De este modo, cuando la junta recomendó el despacho del título correspondiente a Antonio de Guevara, Vázquez comprendió que su última oportunidad residía en explotar las dudas del rey sobre la capacidad del elegido, que le llevaron de nuevo a pedir a Juan Núñez confirmación de los méritos del interesado, así como su opinión a Mateo Vázquez. Fue éste el encargado de recabar los pareceres y, al tiempo que remitía el de Núñez sobre Guevara (alegaba que era «(...) hombre rico y de buena opinión, pretende acrecentarse y a de reventhar porque se vea mejoría grande»), exponía que sería bueno para una correcta elección averiguar el conocimiento de cada candidato sobre la situación exacta de la proveeduría en Sevilla y las posibles soluciones. Lamentablemente para Mateo Vázquez, el monarca respondió que a primera hora de esa misma mañana Delgado le había pasado a la firma el despacho de Guevara, y que había decidido darle curso para no dilatar más el negocio; en todo caso - y después de una pausa para el almuerzo - fuera por contentar a su secretario, pero también porque no se había convencido del todo de la idoneidad del

53 Para todo lo anterior BL. Add. 28237, fols. 265-266 (publicado en RiBa GARcía, Carlos, Correspondencia privada de Felipe II con su secretario Mateo Vázquez (1567-1591), Madrid, Instituto Jerónimo Zurita, 1959, pág. 262), Mateo Vázquez al rey, con respuesta, 14 de octubre de 1581; AGS. GM, leg. 109, núm. 332, Delgado al rey, con contestación, 16 de noviembre; IVDJ. Envío 55, caja 72, carp. 4, fol. 80, Felipe II a Mateo Vázquez, 16 de noviembre. Sobre esta Junta véase FernándeZ ConTI, Santiago, Los Consejos de Estado y Guerra de la Monarquía Hispana en tiempos de Felipe II (1548-1598), Valladolid, Junta de Castilla y León, 1998, pág. 191. 
nombramiento, Felipe II ordenó a Vázquez y Núñez la vigilancia de las actividades de Guevara en su nuevo cargo, con el concurso de gente de crédito en Sevilla «(...) porque si no fuere bien seamos a tiempo de remediarlo» ${ }^{54}$.

De modo que el título provisional de Guevara fue firmado el 24 de noviembre y comunicado, inmediatamente, al interesado, acompañado de una copia de la memoria de la empresa de la Tercera de 19 de octubre, para que se pusiera a la tarea con la mayor celeridad ${ }^{55}$. El nuevo proveedor, como era costumbre, escribió los agradecimientos protocolarios, tanto a Felipe II como al secretario de la Guerra ${ }^{56}$, y unos días más tarde se ocupó de manifestar su gratitud particular a Mateo Vázquez por la cobertura prestada ${ }^{57}$. En este sentido, carecemos de información sobre un posible reconocimiento a su verdadero mentor para el puesto, Juan Núñez de Illescas, pero en adelante Guevara se convirtió en fiel criatura del secretario Mateo Vázquez y bajo su manto alcanzó en 1584 asiento en el Consejo de Hacienda. Tampoco se pudo quejar Andrés de Alva, que en 1586 culminó su carrera al ser elegido primer secretario de Guerra dedicado a asuntos marítimos ${ }^{58}$. Y por lo que toca a Juan Delgado, el sinsabor que le debió producir la constatación de su pérdida de influencia fue paliado, al menos en parte, con la aceptación de su sugerencia para que Pedro de Padilla, maestre de campo, y el capitán Marolín, fuesen con Guevara a Sevilla a dar calor a la organización de la armada ${ }^{59}$.

Si el secretario de Guerra topaba con Mateo Vázquez y sus criaturas en el ámbito logístico de la campaña, en otro aspecto, como era la organización de las tropas de infantería, debía enfrentarse con un adversario muy distinto, el duque de Alba. En efecto, el primer choque entre el noble y el secretario tuvo lugar a propósito de la orden dada a finales de octubre o principios de noviembre para revisar el estado de las fuerzas disponibles en Portugal ${ }^{60}$. Alba y Delgado se pusieron de acuerdo sobre el alcance del proceso, que debía ejecutar el comisario Luis de Barrientos sobre los contingentes del castillo de Lisboa, San Juan y Cascais, en tanto que el proveedor Pedro de Guzmán se encargaba de

${ }^{54}$ IVDJ. Envío 55, caja 72, fols. 87-89, Felipe II a Mateo Vázquez, 22 de noviembre y respuesta de Vázquez (con inclusión del parecer de Núñez) el 24 de noviembre, anotada por el rey.

55 Borrador del título en AGS. GM, leg. 119, núm. 265-2. En la memoria del 19 de octubre se añadió la nota siguiente: «Embiose copia a Antonio de Guevara con carta de 24 de noviembre de 1581, el dicho día». AGS. GM, leg. 119, núm. 229.

56 AGS. GM, leg. 119, núms. 103 y 104, cartas al rey y a Delgado, 28 de noviembre.

57 BPUG. CEF, vol. XXXIII, fols. 90-91, Guevara a Mateo Vázquez, Sevilla, 5 de diciembre de 1581 .

58 Sobre estos dos personajes véase Martínez Millán y De Carlos Morales (dirs.), Felipe II (1527-1598)..., págs. 319-320 y 392-393.

59 AGS. GM, leg. 109, núm. 349, Delgado al rey, 4 de diciembre; el 8 de diciembre el secretario informaba al monarca de la aceptación de la misión por parte de Padilla, que solicitó la consabida merced (AGS. GM, leg. 109, núm. 353). Padilla entró en Sevilla el día de Año Nuevo de 1582 (AGS. GM, leg. 122, núm. 25).

60 Sobre este tema, AGS. GM, leg. 109, núms. 340-343, 23 de diciembre. 
inspeccionar las fuerzas del norte del reino, con base en Oporto. Guzmán efectuó muestra a españoles y alemanes, con fuertes quejas sobre la picaresca de éstos últimos, de los que había tres compañías en Oporto y una en Bayona, ya en Galicia ${ }^{61}$. Pero las dificultades surgieron cuando el duque, al parecer por su cuenta y riesgo, ordenó más tarde a Barrientos que tomara muestra únicamente a los soldados nuevos (asentados desde el mes de marzo, fecha acostumbrada de las levas anuales) de las 21 compañías que constituían la guarnición del castillo de Lisboa. Realizada la inspección el 22 de noviembre, Barrientos informó a Delgado del resultado (faltaban más de 200 hombres del total de 533 alistados), con algunas consideraciones añadidas sobre el fraude generalizado en las plazas de las compañías, con el daño consiguiente a la hacienda regia. Ante el enfado del secretario, Barrientos sólo puedo alegar la orden del duque, que también había servido para superar las reticencias del contador encargado de realizar el conteo. Sumamente molesto, Delgado informó al monarca del incidente, que explicó en el interés del duque por encubrir las posibles deficiencias entre los veteranos.

El hecho de que Felipe II estuviera de acuerdo con Delgado y ordenara realizar nueva muestra en cuanto hubiera ocasión, pero se cuidara mucho de desautorizar abiertamente al duque, da medida del inmenso prestigio atesorado por $\mathrm{Alba}^{62}$. En el ocaso de sus días, continuaba siendo el general más respetado de la Monarquía, circunstancia que, en condiciones normales, ni tan siquiera el monarca podía pasar por alto ${ }^{63}$. Claro que la preparación de una campaña de la importancia de las Azores no era precisamente un negocio de rutina, y el secretario de Guerra encontró el campo más abierto para sus diatribas contra el duque. De este modo, cuando Delgado le requirió sobre el volumen necesario de tropas, Alba pretendió consultar el negocio directamente con el rey, para luego despachar los trámites con el secretario de Guerra, como era su costumbre. La escéptica y dilatoria respuesta del monarca mostró bien a las claras que se hallaba poco dispuesto a contemporizar con el noble, actitud que contrastaba con la atención profesada en la misma relación hacia el emergente Cristóbal de Moura, consultado por el secretario sobre el refuerzo previo de la isla de San Miguel $^{64}$. Y el despacho entre Alba y Felipe II no le sirvió al duque para mejorar las cosas, pues su opinión de que no era menester gran número de gente

${ }^{61}$ AGS. GM, leg. 119, núms. 110 y 111, cartas de Guzmán al rey y a Delgado, 26 de noviembre de 1581 .

${ }^{62}$ AGS. GM, leg. 119, núm. 348. Incluso cuando, al poco, el duque habló al soberano de la necesidad de tomar nuevas muestras, Felipe II comentó a Delgado que «no se si serán mejor que la pasada».

${ }_{63}$ Delgado denunció también el desorden en las compañías de Lisboa y Setúbal, pero el duque de Alba era de opinión que la reforma necesaria era que las compañías nuevas se integrasen en las viejas excepto tres; el rey aceptó la reforma y manifestaba sus dudas a Delgado de que hubiera sido avisado. AGS. GM, leg. 109, núm. 348.

${ }^{64}$ AGS. GM, leg. 109, núm. 352. 
para la jornada chocó frontalmente contra el parecer del soberano - «yo soy muy amigo que en estas cosas sobre más que no que falte»- apoyado de manera entusiasta por Delgado, quien apostillaba que ya se había errado "por no enviar la [gente] que convenía», sin hablar de las amenazas inglesa y francesa, para las que convenía tener armada bien pertrechada ${ }^{65}$.

En suma, a despecho de la recomendación del duque de Alba, a mediados de diciembre Delgado hacía una relación a Felipe II de las fuerzas disponibles para la empresa: los tercios de Lope de Figueroa (a punto de arribar a Cartagena) y Antonio Moreno (que se hacía en Andalucía), 1500 hombres que se levantaban en aquellos momentos en Extremadura, cuatro compañías de las guarniciones del norte de Portugal, diez banderas de alemanes y, posiblemente, mil soldados de los reservados para Larache, caso de que no se llevara a cabo aquella empresa. Al margen de la reseña de cada uno de estos contingentes anotó Felipe II su deseo de aumentar la cantidad, de manera que apostillaba: «y con los que he dicho que crezcan será bueno que pasen de los 10.000 (...) $»^{66}$. Con todo, días más tarde Alba presentaba al monarca una memoria que atestiguaba, concluidas las controversias sobre las muestras, la escasez de hombres que sufrían las unidades presentes en Portugal, y le dejaba convencido de la importunidad de una detracción de recursos que podían debilitar seriamente la defensa del reino recién adquirido ${ }^{67}$. En tales circunstancias, el deseo regio de contar para la jornada con un ejército numeroso solo podía satisfacerse con la leva de nuevas banderas en Castilla, que se ordenó inmediatamente, y el traslado de algunas fuerzas desde Flandes, como, por ejemplo, del tercio de Fernando de Toledo.

Para comandar el ataque a la Tercera, tanto en lo referente a los efectivos marinos como a los terrestres, el primer candidato era don Álvaro de Bazán, marqués de Santa Cruz, quien hacia unos menos rechazara cortésmente la jefatura de la segunda flota enviada al archipiélago. Pero ésta era diferente y más prometedora ocasión, así que cuando Juan Delgado se lo propuso, parece que no dudó en aceptar, bien es cierto que con la consabida petición de merced económica ${ }^{68}$. A reglón seguido, Delgado recomendó, y aprobó el monarca, que después de poner en orden los preparativos en Lisboa, Santa Cruz marchase a Andalucía a impulsar los aprestos de la armada ${ }^{69}$. Por otro lado, Bazán deseaba disponer de un comandante de las fuerzas terrestres, en calidad de maestre de campo general, con dos o tres maestres de campo por debajo, al frente de sus respectivos tercios. Dado que el que había ostentado el cargo hasta el momento en Portugal, Sancho Dávila, tras diversas vicisitudes había sido despachado a

65 AGS. GM, leg. 109, núms. 356 y 361.

${ }^{66}$ AGS. GM, leg. 109, núm. 361, Delgado al rey con contestación al margen, 15 de diciembre de 1581 .

67 AGS. GM, leg. 109, núm. 365, Felipe II a Delgado, 21 de diciembre.

68 AGS. GM, leg. 109, núm. 353, Delgado al rey, 8 de diciembre.

69 AGS. GM, leg. 109, núm. 361, Delgado al rey, 15 de diciembre. 
Gibraltar a ponerse a las órdenes del duque de Medina Sidonia para la empresa de Larache, el militar disponible más capacitado era Lope de Figueroa, que resultaba aceptable para Santa Cruz. Felipe II admitió la sugerencia pues «no creo que dexaran por esto de ir los demás»; es decir, Figueroa tenía reputación suficiente como para asegurar que no se presentase el temido conflicto de precedencias entre los militares ${ }^{70}$; aunque de nuevo, hubo de recurrir a ayuda externa (en este caso al marqués de Aguilar) para convencerle ${ }^{71}$. Uno de los maestres de campo que habían de servir bajo su mando era, lógicamente, el ya en activo Antonio Moreno, pero el rey ordenaba a Delgado mirar «quienes otros podrían ir» ${ }^{72}$.

Lamentablemente, carecemos de documentación que nos ilumine sobre las listas de candidatos que, en cumplimiento de la orden del rey, fueron elaboradas y discutidas en la corte durante las primeras semanas de 1582, cuestión que se asignó al duque de Alba y al Consejo de Guerra. Conocemos, sin embargo, el resultado final: el nombramiento, gracias al conde de Chinchón y, sin duda, con el visto bueno del anciano duque de Alba, de un nuevo maestre de campo, don Francisco de Bobadilla, para dirigir las compañías que hacia meses se ordenaran levantar en Castilla, encuadradas en un tercio. Don Francisco era el segundón de una rama de la familia Arias Dávila, que entonces estaba en pleito por el condado de Puñonrostro ${ }^{73}$. Se había dedicado a la milicia, donde había adquirido una considerable experiencia militar iniciada en Milán como capitán de la guarda del gobernador, el duque de Alburquerque, y acrecentada en Flandes a las órdenes de Alba y de Luis de Requesens ${ }^{74}$.

\section{Movilización en el territorio: el tercio de Bobadilla}

A comienzos de 1582, don Francisco de Bobadilla se encontraba en Valladolid, según sus propias palabras «ayudando a mi hermano en el pleyto que trae sobre el condado de Puñonrostro» ${ }^{75}$. Enredado en los vericuetos de la Chancillería, el 4 de marzo le llegó correo real con noticias más acordes a su

${ }^{70}$ Era capitán en Flandes, fue luego nombrado maestre de campo de un tercio de Milán, plaza desde la que pasó a participar en las campañas de las Azores. Coronó su carrera el 18 de agosto de 1585 cuando fue nombrado capitán general de la costa del reino de Granada, vacante por la muerte de Sancho Dávila AGS. GM. LR, 37, fol. 5v.

${ }^{71}$ AGS. GM, leg. 109, núm. 369, Delgado al rey, 24 de diciembre, informando de las gestiones de Aguilar y algunos problemas referentes al título y sueldo del maestre de campo general.

72 AGS. GM, leg. 109, núm. 363, Delgado al rey, el 20 de diciembre, con contestación.

73 Sobre este linaje, FERNÁNDEZ CONTI, Santiago, «La nobleza castellana y el servicio palatino», en: MARTíneZ Millán y FernándeZ ConTi (dirs.), La Monarquía de Felipe II..., vol. I, págs. 608-609.

${ }_{74}$ Memorial de servicios en AGS. GM, leg. 182, núm. 132.

75 AGS. GM, leg. 129, núm. 140, Bobadilla al rey, 4 de agosto de 1582. 
vocación guerrera. Con fecha de 23 de febrero, el monarca había decidido nombrarle maestre de campo de un nuevo tercio, cuyas compañías se levantaban en ese momento en Toledo, la Mancha, el marquesado de Villena y Mur$\mathrm{cia}^{76}$. El propio don Francisco debía formar una bandera en las villas de Talavera de la Reina, Puente del Arzobispo y en las tierras de los condados de Orgaz, Oropesa y Fuensalida; unidad que si en la conducta inicial debía estar formada por 200 hombres, se rectificó inmediatamente para aumentarla a 400, al igual que sucedió con las otras doce banderas que completaban el tercio ${ }^{77}$. El ascenso en su carrera militar fue agradecido como era menester por Bobadilla, que no escatimó las alabanzas al Rey Prudente ${ }^{78}$, sin descuidar la atención debida al secretario Delgado quien, a pesar de los desvelos de don Francisco, mantuvo siempre una fría cortesía en su correspondencia con el militar ${ }^{79}$.

El tercio de Bobadilla era una pieza más de la amplia movilización de fuerzas que se pretendía en los reinos ibéricos, a fin de atender a los varios objetivos de la Monarquía. Al tiempo que se firmaba su ascenso, desde la corte se despachó correo a Palencia para ordenar a Luis Enríquez se sirviese reactivar la leva de su tercio ${ }^{80}$, en tanto que Antonio Moreno había sido apercibido a principios de enero para arreglar cinco o seis compañías, hasta un total de 2000 hombres, que debían sustituir a los enviados al duque de Medina Sidonia para la jornada de Larache; claro que Moreno, a pesar de verse recompensado aquellos días con jugosa encomienda, manifestó su perplejidad por la orden, dado que todavía no se le habían enviado la media docena de capitanes para sustituir a los embarcados, y del resto varios capitanes estaban sin localizar ${ }^{81}$. Por lo que toca al tercio de Figueroa, a tres de marzo, habían zarpado las galeras de Juan Andrea Doria para traerlo de Orán, y su jefe advertía sobre la falta de hombres, dinero, vituallas y equipo ${ }^{82}$. No es de extrañar, por tanto, que cuando Álvaro de Bazán entró en Sevilla, el 13 de marzo, y después de informarse del estado de las unidades, expresara su escepticismo sobre las ambiciosas pretensiones de reclutamiento. Según aducía en carta a Delgado, disponer de mil

${ }^{76}$ El título en ACP. B-2b, caja 10-4a, carta del rey a Bobadilla para notificar el nombramiento. Los capitanes fueron los siguientes, con sus zonas de reclutamiento: Francisco de Vargas (Alcalá de Henares y Guadalajara), Hernando Pacho (Maqueda, Torrijos y Escalona), Gaspar Funes de Flores (priorazgo de San Juan y la Mancha), Juan de Salcedo (Ciudad Real y Almagro), Francisco Rengifo y Lope de Salazar (ambos en el marquesado de Villena), Pedro Muñoz de Castilblanco (Alcaraz y su tierra), Pedro Pardo (Yepes y Ocaña), Pedro Pliego (Talavera y Puente del arzobispo), Diego Suárez de Salazar (Cuenca, Huete y su tierra) y Juan de Luna y Juan de Vivero (ambos en Toledo y su tierra).

77 ACP. B-2a, B-2c. Las instrucciones para la leva en caja 10-5a.

78 AGS. GM, leg. 124, núms. 256 y 257, Bobadilla al rey y al secretario Juan Delgado, 9 de marzo de 1582; contestada por el monarca el 19 de marzo, ACP, caja 10-4e.

${ }^{79}$ Las cartas de Delgado a Bobadilla durante estos meses se conservan en ACP, caja 10-5b-5f.

80 AGS. GM, leg. 124, núm. 145.

${ }^{81}$ AGS. GM, leg. 122, núm. 12, leg. 125, núm. 193.

82 AGS. GM, leg. 124, núm. 153, Figueroa a Delgado el 6 de marzo de 1582. 
soldados para Italia (para reemplazar a los trasladados a Castilla), 3500 para Larache, 2000 para Lisboa (refuerzo de las guarniciones) y 12000 para la Tercera, resultaba harto problemático en el escaso tiempo previsto. De todas formas, se dispuso a cumplir la orden regia de enviar de inmediato por mar a la capital portuguesa dos mil hombres, que debían ser los de la unidad de Bobadilla. Para ello, planificó el embarque de las banderas en Cartagena y en el Puerto de Santa María, y dio a Bobadilla y a los capitanes las instrucciones pertinentes, si bien, con mucho fundamento, dudaba de la inmediata disponibilidad de las tropas ${ }^{83}$.

El 17 de marzo tuvo lugar en Lisboa la reunión de una junta especial convocada para tratar del dispositivo militar que sería necesario para atender a la defensa de la península y de la Carrera de Indias ${ }^{84}$. Entre las numerosas cuestiones a tratar, cuidadosamente revisadas por el monarca, se incluía la recomendación para que se impulsara el levantamiento de los tercios de Luis Enríquez, Antonio Moreno y Francisco de Bobadilla, así como de las compañías que se aprestaban en Extremadura; mientras la primera unidad se destinaba a la comarca portuguesa de Entre Douro e Minho, las restantes debían encaminarse de un modo u otro hacia Lisboa. Desconocemos el resultado final de las deliberaciones de la junta, pero al menos este punto parece que fue aprobado, dado que dos días más tarde Felipe II firmaba una carta apremiando al maestre de campo la formación de las compañías y la marcha hacia Portugal. Y había una novedad, pues, atendiendo a las reiteradas advertencias de Santa Cruz, se decidió que el camino había de ser por tierra y no por mar, medio de transporte que se asignaba ahora al tercio de Moreno ${ }^{85}$. La misiva fue recibida por don Francisco el día 23, cuando hacía cuatro que entrara en Talavera de la Reina, su centro de operaciones durante las semanas siguientes. En su contestación al soberano informaba de su tardanza en abandonar Valladolid, ocupado en preparativos diversos y su marcha final, acompañado por Juan de Palomares (que había servido mucho tiempo con el duque de Alba) con el cargo de capitán de campaña; de camino, en Madrid y Toledo, había despachado correo a sus capitanes para anunciar su llegada y las órdenes regias. También se alegraba, por último, de la decisión tomada en la corte de que su tercio marchara en bloque, en lugar de su división para el embarque en Cartagena y el Puerto de Santa María ${ }^{86}$.

83 AGS. GM, leg. 124, núms. 4-8, Bazán al rey y a Delgado, 16, 18 y 20 de marzo de 1582. La relación del embarque de las compañías en núm. 36.

${ }_{84}$ AGS. GM, leg. 135, núm. 35, se halla un borrador del orden del día, corregido y anotado por el rey de su puño y letra; la versión definitiva del documento en núm. 34. Según Herrera y Tordesillas este fue el momento en que se tuvo la certeza de que la armada francesa habría de buscar las flotas de Indias, por lo que se decidió la llamada a Portugal de los tercios que se levantaban en Castilla, HerRera y TORDESILLAS, Cinco libros..., págs. 163-164.

85 AGS. GM, leg. 124, núms. 10 y 11, Bazán al rey y a Delgado, 23 de marzo, acatando con satisfacción la nueva orden respecto a Bobadilla pero recomendando de nuevo que el tercio de Moreno siguiera la misma vía terrestre, petición rechazada.

86 ACP, caja 10-4d, carta del rey de 19 de marzo, que fue contestada por don Francisco el 24, el mismo día que escribía al secretario Delgado. AGS. GM, leg. 124, núms. 258 y 259. 
Mientras don Francisco se entrenaba como maestre de campo, en la corte de Lisboa crecía la actividad ante el inicio de la próxima campaña. Había también seria preocupación por la actitud de Francia, sospechas acrecentadas con la llegada de ciertos avisos sobre su armada. La circulación de la información en la corte de Felipe II nos ilustra una vez más sobre sus métodos de gobierno y la posición de sus ministros. Habían llegado los documentos a manos de Juan de Idiáquez, que de inmediato los puso en conocimiento del monarca; éste, a su vez, los pasó al secretario Delgado, pero no permitió que fueran mostradas en la junta mencionada del día 17 — con la particular excepción de Juan Núñez y Antonio de Eraso-, aunque sí al duque de Alba. Unos días más tarde, el anciano general recomendaba al secretario el envío de una nao a la costa de Francia a fin de realizar averiguaciones ${ }^{87}$. Sin embargo, para entonces el rey había leído un memorial, que incidía en la posibilidad de que la flota gala diera algún golpe de mano en la costa. Consultado de nuevo Alba sobre el particular, adujo que, como quiera que resultara imposible prevenir todo el perímetro costero, la única solución consistía en tener fuerzas preparadas para rechazar el golpe, para la cual urgía, además de la adecuada protección de la persona real, la prevención de las galeras y la llegada de los tercios que se levantaban en Castilla. Felipe II estuvo de acuerdo con el diagnóstico del duque, de manera que ordenó acelerar la expedición del título necesario precisamente al hijo de Alba, el prior don Hernando de Toledo, para mandar las tropas estacionadas en la comarca de Entre Douro e Minho, operación que se discutía en la corte desde hacia varias semanas ${ }^{88}$. De todos modos, al margen del refuerzo de la costa con las tropas disponibles —incluido el tercio de Luis Enríquez-, la leva en curso de las compañías en Castilla fue afectada por una nueva actualización de la información del rey, que indicaba que la temida flota no saldría hasta finales de abril o el mes de mayo. Por ello, en sus propias palabras:

«(...) aunque sería bien que estuviera aquí la gente a tiempo, tampoco querría que estuviese mucho antes, que haría daño (...) por esto me paresce que baya oy la carta de don Francisco de Bobadilla, por estar más lejos, y la de Extremadura por estar más cerca se puede entretener un poco más (...)»89.

87 AGS. GM, leg. 135, núms. 32 y 39.

88 Título fechado el 3 de abril. AA, caja 53, núm. 88; sobre el prior véase FerNáNDEZ CONTI, Santiago, «El prior don Hernando de Toledo, capitán de Felipe II y de sus Consejos de Estado y Guerra», en: FANTONI, Marcelo (dir.), Il <perfectto capitano >: immagini e realtà (secoli $X V$-XVII), Roma, Bulzoni, 2001, págs. 87-134 (págs. 127 y ss para el cargo en Portugal). Sobre este empeño Fernández Conti, Santiago y Labrador Arroyo, Félix, «Entre Douro e Minho. El Prior don Hernando de Toledo y Portugal», en: Ruiz Gómez, Francisco y Molero García, Jesús M. (eds.), La Orden de San Juan entre el Mediterráneo y la Mancha, Cuenca, Universidad de Castilla-La Mancha, 2009, págs. 367-383.

89 AGS. GM, leg. 135, núm. 40, Delgado al rey con contestación hológrafa del monarca, 26 de marzo de 1582. 
En efecto, el mismo día 26 de marzo, salió de Lisboa correo para apremiar a don Francisco el levantamiento y puesta en camino de su tercio, una vez que hubieran llegado los pagadores enviados desde Sevilla por Antonio de Guevara ${ }^{90}$. El mensajero le encontró en Talavera, inmerso en la tarea de formar su propia compañía, al tiempo que coordinaba el resto de las banderas y asentaba la organización de la unidad. Como era costumbre, los distritos en los que debía operar habían sido apercibidos mediante real cédula para facilitar en lo posible las levas y ordenar la forma de hacer justicia en caso de posibles alborotos ${ }^{91}$. Debido a la dificultad de encontrar hombres apropiados, el 30 de marzo, hizo una rápida escapada a la vecina localidad de Puente del Arzobispo, pues la celebración en aquellos momentos de dos días de feria era siempre favorable al reclutamiento, por la aglomeración de la gente. En lo que se refiere al resto del tercio, conoció una pieza clave de su estructura, el sargento mayor, y mantuvo contacto permanente con todos sus capitanes. De todos modos, don Francisco no dudaba en achacar la tardanza en las levas a la ausencia de los pagadores, oficiales que debían hacer efectivos los llamados «socorros» a los soldados y que disponían de estrictas instrucciones para el manejo del dinero ${ }^{92}$. El maestre general atribuía su tardanza a oscuros manejos, ligados a los intereses más o menos espurios que escondían.

Hasta el cinco de abril no llegaron dos pagadores —el de su compañía y el de la del capitán Pedro Pliego- y un par de días más tarde lo hicieron el resto a sus respectivos distritos ${ }^{93}$. Se había estipulado el pago de tres socorros antes de su llegada a Lisboa. El retraso se vio compensado con el aumento de gente «(...) porque se an crecido mucho las compañías con la nueba de los pagadores». El mismo día 5 llegó una segunda versión del itinerario que debía seguir para dirigirse a Portugal —el primero había llegado el 26 de marzo- preparado cuidadosamente en la corte. La ruta incluía la marcha hasta Plasencia, para a continuación embarcar en algún punto del Tajo, donde le estaría esperando con las barcazas necesarias el ingeniero Juan Bautista Antonelli, quien el año anterior había recibido la misión de explorar las posibilidades de transporte marítimo del río $^{94}$. La entrada en el vecino reino sería, pues, a través del río, con paradas en Abrantes y Santarém, y Lisboa como destino final. Pudo entonces don Francisco comunicar la ruta a los distintos capitanes, a los que pidió

90 ACP, caja 10-4f, carta del rey a Bobadilla, recibida el día 29, el maestre de campo respondió a Delgado el postrero de marzo; AGS. GM, leg. 124, núm. 260.

${ }_{91}$ ACP, caja 10-4c, cédula real fechada el 23 de febrero.

92 A cada recluta se le debía de hacer su asiento con nombre, edad, señas de naturaleza, al tiempo que el pagador, de su mano, los socorría, según la siguiente forma: capitán, $1388 \mathrm{mrs}$., alférez, 600, dos tambores, 600, pífano, 600, capellán, 680, cabos (uno por cada 25 hombres), 600 y soldados a 300 .

${ }_{93}$ ACP, caja 10-4g, 10-5d y 10-5e, cartas de Felipe II a Bobadilla, de 2 de abril, y de 22 de marzo y 2 de abril del secretario Delgado; AGS. GM, leg. 125, núm. 25, respuesta de don Francisco al rey de 7 de abril.

94 AGS. GM, leg. 109, núm. 81. A mediados de abril, Antonelli regresaba, cumplida la misión, y presentaba la memoria deseada. AGS. GM, leg. 109, núms. 72 y 90. 
informasen a la mayor brevedad del número final de hombres que habían logrado reclutar. Planificó un orden de marcha riguroso. Las compañías debían andar de dos en dos, a fin de no recargar en demasía los alojamientos. Las seis que se hacían en la Mancha y el marquesado de Villena serían encabezadas por la del capitán Gaspar Funes de Flores, acompañada de las de Juan de Salcedo y Diego Suárez de Salazar y seguidas de las banderas de Francisco Rengifo, Lope de Salazar y Pedro Muñoz de Castilblanco. Respecto a las siete unidades restantes, la vanguardia estaba reservada al capitán Francisco de Vargas - la más alejada, pues partía de Alcalá de Henares-, acompañado de las tropas de Pedro Pardo y Hernando Pacho ${ }^{95}$. Con todo, todavía hubo una demora, con cierta alteración de los planes iniciales. En carta de 9 de abril el monarca tornaba a apremiar al secretario de Guerra, cuya contestación se reservaba para cuando las compañías estuvieran en marcha. Argumentaba el maestre de campo la dilación de las tropas de Francisco de Vargas, al que sin embargo recomendaba para dirigir una compañía de arcabuceros ${ }^{96}$.

De modo que a principios de abril don Francisco estaba casi dispuesto para iniciar la marcha hacia Portugal y el resto de las unidades destinadas a aquel reino se encontraban más o menos en la misma situación. Así, el día 7, llegaron a la bahía de Cádiz dos naos con las cinco compañías de Flandes del tercio del maestre de campo don Fernando de Toledo, y fueron transportadas por río hasta sus alojamientos en Lebrija ${ }^{97}$; por su parte, Luis Enríquez informaba el día 17 que, llegados los pagadores, se había puesto en camino ${ }^{98}$, mientras que Antonio Moreno, un poco más retrasado, continuaba con dificultades para hacerse con el suficiente número de hombres ${ }^{99}$. En parecida tesitura se hallaba Lope de Figueroa, quien el 20 de marzo había completado el desembarco de su tercio en Cartagena, procedente de Orán; pero se hallaba tan disminuido, con poco más de un millar de soldados, que el maestre de campo hubo de enviar de inmediato 10 capitanes a buscar gente con que rehacer las compañías (entraron en competencia con los de Bobadilla), de modo que hasta el 16 de abril no pudo hacer muestra completa de su unidad en el puerto ${ }^{100}$. Ese fue el día, por último, en que el capitán Agustín Iñiguez, a quien se había encomendado la dirección de las siete compañías levantadas en Extremadura, llegó a Herrera de Alcántara, localidad ribereña del Tajo donde le esperaba el ingeniero Antonelli para transportar las banderas río abajo, hacia Lisboa ${ }^{101}$.

95 AGS. GM, leg. 125, núm. 26, carta de Bobadilla a Delgado de 7 de abril de 1582.

96 ACP, caja $10-4 \mathrm{~h}$, carta de Felipe II a Bobadilla de 9 de abril; la respuesta, dirigida a Delgado el día 15, en AGS. GM, leg. 125, núm. 27; el rey se dio por enterado por consulta del secretario, como reflejaba en carta a Bobadilla de 23 de abril. ACP, caja 10-4i.

97 AGS. GM, leg. 125, núm. 130, Bazán al rey, 8 de abril.

98 AGS. GM, leg. 125, núm. 337, Enríquez al rey, 17 de abril.

99 AGS. GM, leg. 125, núm. 193, Moreno a Delgado, 10 de abril.

100 AGS. GM, leg. 124, núms. 153-155, Lope de Figueroa al rey y a Delgado, 6 y 21 de marzo; leg. 125, núm. 317, muestra del tercio en Cartagena el 16 de abril.

101 AGS. GM, leg. 125, núms. 154 y 161, Antonelli al rey, 16 y 28 de abril. 
Al tiempo que los maestres de campo y capitanes concluían la leva de sus banderas y se ponían en ruta, en la corte, decidida ya a grandes rasgos la estrategia militar de la temporada y puestos en marcha los elementos pertinentes, habían disminuido un tanto la tensión consultiva y organizativa. Quizá por ello Mateo Vázquez pudo aprovechar una circunstancia inesperada, la muerte de Juan Núñez de Illescas, para arremeter contra la posición de Juan Delgado, en beneficio de uno de sus protegidos más sobresalientes, Antonio de Eraso. En realidad, achacoso ya Delgado y pendiente del resultado de una «visita», acaso se pensaba ya en un retiro decoroso. Es sintomático que a mediados de marzo de 1582 recibiera una jugosa merced de 2000 ducados por una vez, aunque no dejó de quejarse de que la suma casi no alcanzaba a cubrir sus elevadas deudas ${ }^{102}$. Apenas un mes después Vázquez indicaba a Juan Delgado que debía de entregar a Antonio de Eraso los papeles de la Junta de Hacienda; la maniobra quedaba concluida el 20 de mayo, cuando, ante las protestas del secretario de Guerra, Felipe II hacía oficial el cambio, con la creación de una sola Junta, llamada «de Santo Domingo», fusión de todos los círculos dedicados a negocios de Hacienda, Indias, Castilla, Cámara y Cruzada, y en la que Eraso quedaba como secretario ${ }^{103}$.

Acaso avisado por sus contactos de la cambiante situación en la corte, don Francisco de Bobadilla continuaba inmerso en la difícil tarea de dirigir el camino de su tercio. El 22 de abril, todavía en Talavera, podía sin embargo informar al rey de que las siete compañías levantadas en Toledo y en el marquesado de Villena llevaban buena marcha: unos días antes, el miércoles 18, había ordenado hacer la muestra a dos leguas de Talavera de las cuatro de vanguardia, para que los hombres recibieran el dinero lejos de sus tierras. Éstas habían partido el 20 de abril, a cargo del sargento mayor, y estaban a punto de llegar a Plasencia. Por lo que se refiere a las otras tres compañías, el retraso ya referido de la bandera de Vargas había alterado los planes iniciales, así que Bobadilla dispuso la andadura de las dos restantes para no alejarse en demasía de la vanguardia, mientras que Vargas les seguía con una jornada de diferencia ${ }^{104}$. Entre las siete sumaban 1690 hombres, lejos pues de los 2800 reclutas programados inicialmente; únicamente la bandera del retrasado Vargas había alcanzado la cifra propuesta de 400 hombres. A este respecto, se quejaba Bobadilla de que los dos capitanes que operaron en el marquesado de Villena habían sufrido dura competencia de los oficiales del tercio de Lope de Figueroa, pues mediante el ofrecimiento de un real diario más alojamiento, habían logrado sustraer numerosos mozos ya alistados de las compañías de Bobadilla. El movimiento de parte del tercio, por último, le sirvió a Bobadilla para reclamar una ayuda de costa para cubrir los grandes gastos que había hecho desde su salida de Valla-

\footnotetext{
102 AGS. GM, leg. 125, núm. 299, Delgado al rey, 17 de marzo.

103 BL. Add. 28.358, fol. 54; AGS. GM, leg. 137, núms. 113-114 y 125-133.

104 AGS. GM, leg. 125, núms. 28 y 29, cartas de Bobadilla al rey y a Delgado.
} 
dolid, y porque además el pagador asignado a su compañía no le quería siquiera abonar los estipendios realizados en correos ${ }^{105}$.

El 24 de abril, una vez que las tres compañías de retaguardia entraron en Talavera, don Francisco partió al galope hacia Malpartida de Plasencia, donde entró al día siguiente, al tiempo que lo hacía el sargento mayor con las cuatro compañías de vanguardia. A esas alturas, todavía no podía asegurar al rey la partida de las seis compañías de la Mancha. Ya en el camino, una de las principales preocupaciones del maestre de campo era la asistencia a los soldados. Por un lado, pidió a la corte que en el lugar fijado para dotar de armamento a la tropa hubiera también buen número de trajes, porque parte de los reclutas carecían de vestimenta apropiada. Por otro, debía contener con la rígida actitud de los pagadores, con los que mantuvo un conflicto soterrado a lo largo de toda la campaña.

Los motivos de discordia eran fundamentalmente dos. En primer lugar, según sus instrucciones, los pagadores habían de facilitar a los soldados el socorro necesario cada diez días. Dado que el primero se repartía en el momento de la muestra — que, como hemos dicho, se había retrasado porque no recibieran el dinero cerca de su tierra - cabía la posibilidad de que los reclutas llegasen al punto de embarque, dos o tres jornadas antes de cumplir el tercer socorro (es decir, a los veinte días). Don Francisco había recibido el mandato de que pagasen sus vituallas en las barcas, por lo que solicitó al rey y al secretario de Guerra que se adelantase el tercer socorro. Esta petición la repitió en un par de ocasiones, y llegó a demandar que los socorros se diesen a su orden y no según las rígidas instrucciones de los pagadores.

En Malpartida, don Francisco decidió un breve descanso, tanto por carecer de noticias de Antonelli como por el cansancio de los soldados. Apenas unas horas, debido al desgaste de la tierra y la amenaza de las deserciones, que comenzaban a menudear. Desde ese pueblo, el maestre de campo cabalgó con dos compañías hasta Serradilla. Allí tuvo correo del ingeniero sobre la embarcación, que había de ser en Herrera de Alcántara. Esperaba éste las barcas precisas para llevar seis compañías del capitán Agustín Iñiguez, que habrían de regresar para recoger a su tercio. Debía, pues, entretenerse hasta que le llegase el turno. Sugería también el italiano que las armas las recogiera en Brozas en lugar de Valencia de Alcánta$\mathrm{ra}$ - donde las había recogido Iñiguez — para no alejarse del camino ${ }^{106}$.

El siete de mayo don Francisco entraba en Herrera con tres compañías - la suya, la de Luna y la de Vivero- y la misma tarde tomó muestra, repartió socorro y embarcó las banderas en 28 barcas (más de 650 soldados) al mando del sargento mayor, que llevaba el encargo de dar cuenta al secretario Delgado. Sin embargo, la nao del oficial tuvo un accidente, y éste y otras dos personas

105 AGS. GM, leg. 125, núm. 30 se conserva la relación de las siete compañías. Por lo que toca a las cuatro de vanguardia, la compañía de Bobadilla traía 350 soldados, 220 la de Pliego, 200 la de Juan de Luna y 200 la de Juan de Vivero; respecto a las tres de retaguardia, la de Vargas contaba con 400 hombres, 220 la de Pacho y 200 la del Pardo, a salvo ésta última de la muestra.

106 AGS. GM, leg. 125, núms. 31 y 32. 
perecieron ahogadas, con gran desconsuelo de don Francisco, que perdía un excelente soldado. Quedó entonces la gente a cargo del ayudante del sargento mayor, en tanto se nombraba otro, mientras que el maestre de campo esperaba a las cuatro compañías restantes, que debían ir en el segundo viaje. Como manifestaba en posdata al secretario Delgado, marcharía por tierra a Lisboa si no fuera porque, con su ejemplo, animaría a los soldados a embarcar ${ }^{107}$.

Embarcado don Francisco con las cuatro banderas, navegó hasta Abrantes, y el 16 de mayo desembarcaba en Santarém, lugar en el que hizo alto por orden del duque de Alba. No gustó de la parada y suplicó una rápida orden de movimiento, porque el lugar era caro y los soldados debían gastar dos reales al día, cuando su socorro - que de todas formas los pagadores no querían soltar- apenas llegaba a uno. En consecuencia, despachó al alférez Gonzalo de Molina a informar a la corte y, de paso, suplicar su ascenso a sargento mayor, oficio que le hacía mucha falta. El 20 de mayo estaba todavía en Santarém y pedía se ordenase al pagador abriese la bolsa para mantener a la gente; el 23 obtuvo un préstamo del adelantado don Martín de Padilla de dos mil reales para mantener a la gente, mientras que los pagadores de dos compañías se habían ausentado - uno sin licencia y el otro con permiso- y peligraba el pago de las dos compañías. El 23 de mayo, el mayordomo de la artillería del castillo de Lisboa, Baltasar de Navarrete, entregaba el armamento necesario a las compañías (20 años después el erario regio seguía reclamando a don Francisco parte del monto de la transacción ${ }^{108}$ ). Al día siguiente, pedía el pago debido a los patronos de las barcas, que seguían detenidos en Santarém ${ }^{109}$. Ese mismo día partió la primera compañía de Santarém — la de Pacho- y otras tres lo hicieron al día siguiente, según plan ordenado por el duque de Alba ${ }^{110}$. Las seis compañías restantes todavía tardaron unos días en llegar ${ }^{111}$.

El 29 de junio hubo muestra general en Lisboa de la tropa reunida para el asalto de las Azores, embarcada a continuación en los navíos preparados al efecto $^{112}$. Constaba la expedición de tres tercios —-Lope de Figueroa, Francisco

107 AGS. GM, leg. 126, núms. 145 y 146, Bobadilla al secretario Juan Delgado, 8 de mayo.

108 AGS. CMC, $3^{a}$ época, leg. 3519, núm. 11, «Recepta de los cargos que contra él resultan por los libros de quentas de la comisión de Lisboa», con anotación de haberse trasladado en diciembre de 1604 a otro libro de cargos. La compañía de Juan de Luna recibió 10 mosquetes y 142 arcabuces; la de Juan de Vivero 10 mosquetes, 52 picas y 80 arcabuces; la del propio Bobadilla, 16 mosquetes, 134 arcabuces y 80 picas, equipo que completó el 3 de julio con otros 12 arcabuces.

109 AGS. GM, leg. 126, núms. 147 al 151, Bobadilla al rey y al secretario Delgado, 17 de mayo, y a Delgado de 20, 22 y 24 de mayo.

110 AGS. GM, leg. 126, núm. 153, Bobadilla al secretario Delgado, 24 de mayo.

111 Según Herrera y Tordesillas Bobadilla llegó con sus hombres a Lisboa el 8 de julio, dos días antes de la partida de la armada, habiendo hecho desde Alcántara 56 leguas en dos jornadas. La documentación nos ha demostrado que no fue así, aunque quizá se refiriera el cronista a las seis banderas restantes del tercio, Herrera y TORDESILLAS, Cinco libros..., pág. 164.

112 Cesáreo Fernández Duro publica el resultado de la muestra en: La conquista de las Azores..., doc. 40. Además, en AGS. GM, leg. 146, núm. 74 se conserva la «relación de la manera que va 
de Bobadilla y Antonio Moreno_- más tres compañías de Oporto, siete provenientes de Extremadura, a cargo del capitán Agustín Iñiguez, cinco compañías viejas del tercio de Fernando de Toledo y otras seis al mando de Cristóbal de Eraso. Participaban, además, tres compañías de alemanes (520 hombres), más de 80 entretenidos y aventajados, 64 caballeros y particulares y 120 criados y aventureros. En total, embarcaron 5369 hombres de guerra y 1904 marineros. La cantidad total suponía una merma considerable respecto a las tropas reclutadas.

\section{CONCLUSIÓN}

La batalla de la isla de San Miguel, que enfrentó al marqués de Santa Cruz con la flota francesa al mando de Strozzi el 26 de julio de 1582, ha sido descrita por los cronistas con todo lujo de detalles, incluido el papel desempeñado por Bobadilla. Después de la victoria militar, que no le dio la posesión total de las islas aunque si garantizó el comercio con las Indias y eliminó, de manera momentánea, la amenaza inglesa y francesa, el 4 de agosto, desde la urca San Pedro, don Francisco pedía licencia para continuar asistiendo a su hermano en Valladolid, «(...) porque es solo, y nuestros contratos muchos y poderosos», y se ofrecía para volver a servir en primavera ${ }^{113}$. En realidad, el monarca había pensado en su persona para comandar las fuerzas que habían de quedar en guarnición en San Miguel, y don Álvaro de Bazán así lo comunicó al maestre de campo; pero éste se excusó de nuevo y ante los requerimientos de Santa Cruz, que argumentaba que con la presencia en Valladolid de su hermano era suficiente, respondió don Francisco que «(...) no bastaba, y convenía mucho que él fuese y que por ser jornada tan breve vino a servir a Vuestra Magestad en ella» ${ }^{114}$. En consecuencia, después de la triunfal entrada de Bazán en Lisboa, el 10 de septiembre, acompañado de los «maestres de campo, caballeros, capitanes y otras personas principales (...)» ${ }^{115}$, el tercio de don Francisco fue reformado ${ }^{116}$ y su comandante regresó a Castilla a defender los intereses de su familia durante el invierno, porque en la primavera del año siguiente, como había prometido, se hallaba de nuevo en campaña, y todavía le esperaba una luenga carrera al servicio de la monarquía, que coronó en la corte de Felipe III como consejero de Estado y Guerra, ya titulado IV conde de Puñonrostro.

\footnotetext{
embarcada la infantería en la armada que va a la Tercera» (se refiere a a expedición de 1582, aunque se conserva entre papeles de 1583); la diferencia entre ambas relaciones es de tres soldados más en la segunda (1 803 y 1806$)$.

113 AGS. GM, leg. 129, núm. 140, Bobadilla al rey, 4 de agosto de 1582.

114 Carta de Bazán al rey, de 14 de agosto. (Fernández Duro, La conquista..., doc. 51) y Felipe II al mismo, 22 de agosto. (FerNÁNDEZ Duro, La conquista..., doc. 55).

115 Herrera y TORDESILlas, Cinco libros..., pág. 183.

116 ACP, caja 10-6b.
} 
La preparación de la campaña de las Azores de 1582 pone, a su vez, de manifiesto, las disputas que se dirimían en el seno de la corte, tanto en Madrid como en Lisboa, entre los principales cortesanos por alcanzar la gracia real y por imponer su visión de la estrategia militar de la Monarquía, los cuales no dudaban en utilizar sus conocimientos y sus contactos para alcanzar sus metas políticas. Estas disputas, como hemos visto, también estaban presentes a todos los niveles, aunque no siempre seamos capaces de detectarlos o calcular sus efectos y muchos de los nombramientos estaban motivados por las relaciones que los elegidos tenían en el ámbito cortesano, tal y como ocurrió con don Francisco de Bobadilla, en cuya elección tuvo mucho que ver el conde de Chinchón. En los preparativos de la citada campaña hemos observado, también, la caída en desgracia del secretario de Guerra, Juan Delgado, persona que alcanzó a comienzos de la década de 1580 su máximo apogeo en el poder, después de la caída del secretario Antonio Pérez; así como del proveedor general Francisco Duarte, sustituido en estos momentos por Antonio de Guevara, que ejercía como almojarife mayor de Indias, persona vinculada al consejero Juan Núñez de Illescas y que a la sombra de Mateo Vázquez realizó una interesante carrera política.

Finalmente, el análisis de la evolución de las tropas durante los preparativos de la campaña de 1582 a través, fundamentalmente, de la formación del tercio de Bobadilla en la Mancha ha tenido la virtud, asimismo, de mostrarnos las grandezas y miserias de la política militar del gobierno del Rey Prudente. Grandezas por el tamaño de sus dominios y por las complejidades de sus problemas, en los que una unidad militar era solamente una pequeña pieza dentro del inmenso escenario, en el que era capaz de moverse gracias al establecimiento de una burocracia militar (proveedor, pagador, etc.). Y miserias porque, precisamente por las características del vasto conglomerado patrimonial, Felipe II no tenía un programa militar concreto y sus actos estaban mediatizados por la realidad del momento, como la derrota de la armada de Valdés. Muchas decisiones y medidas eran tomadas atendiendo a la inmediatez de la situación, que estaban motivadas por las circunstancias, y a los vaivenes de los procesos políticos.

Recibido: 26-01-2009

Aceptado: 15-07-2009 